Raul Ramos ORCID iD: 0000-0003-0047-0793

\title{
Revisiting interregional wage differentials: New evidence from Spain with matched employer-employee data
}

\author{
Inés P. Murillo Huertas \\ Universidad de Extremadura \\ Raúl Ramos \\ AQR-IREA, Universitat de Barcelona \& IZA \\ Hipólito Simón \\ Universidad de Alicante-IEI
}

\begin{abstract}
This article examines wage differences across Spain's NUTS-2 regions along the entire wage distribution based on matched employer-employee microdata from 2006 to 2014. Unlike previous related studies, we properly control for differences in regional purchasing power parities, which are very large in practice. Although part of the raw regional wage differences observed are explained by differences between regions in productive structures and, to a much lesser extent, in labor forces, noteworthy, very similar throughout the wage distribution regional differences net of composition effects arise even after controlling for a broad set of individual and firm characteristics.
\end{abstract}

Keywords: interregional wage differentials; decomposition methods; matched employer-employee data; wage setting institutions.

JEL Codes: J31, J52

\section{INTRODUCTION}

Geographical wage differences within a country are usually large and a relevant issue from a policy perspective. The literature has identified several factors that help to explain the magnitude and nature of these spatial wage differentials. According to Combes, Duranton and Gobillon (2008), these different factors can be grouped into three categories: composition effects, amenities and agglomeration economies. In particular, geographical wage differences could reflect spatial differences in the composition of the workforce and firms, non-wage amenities and/or the interactions between workers and firms that contribute to increase the productivity at the local level. The specific causes behind interregional wage differentials and their changes over the years are of great interest, as policy

This article has been accepted for publication and undergone full peer review but has not been through the copyediting, typesetting, pagination and proofreading process, which may lead to differences between this version and the Version of Record. Please cite this article as doi: 10.1111/jors.12459. 
implications depend upon the nature of these factors. Hence, as Pereira and Galego (2011) note, differences in interregional wages caused by non-human amenities such as the climate do not require policy interventions, whereas measures to improve competitiveness can alleviate interregional wage disparities caused by inefficiencies in the allocation of resources among regions. In the same line, policies devoted to enhancing worker and firm productivity in low-wage regions may be insufficient to close the gap if non-competitive factors, such as labor market institutions, also influence regional wages (Simón, Ramos \& Sanromá, 2006).

The examination of spatial wage differentials and the causes behind them has received quite some attention in the literature, covering a variety of countries, such us the UK (Blackaby \& Manning, 1990, 1995), France (Combes et al., 2008), Germany (Kluge \& Weber, 2018), the Netherlands (Groot \& de Groot, 2011; Groot, de Groot \& Smit, 2014), Spain (Motellón,López-Bazo \& Attar, 2011), Italy (Matano \& Naticchioni, 2012, 2016), and Portugal (Vieira, Couto \& Tiago, 2006; Pereira \& Galego, 2011, 2014; Galego \& Pereira, 2014). Two different strands can be identified in this literature. The first strand, whose seminal study is Combes et al. (2008) and where subsequent related analyses can be found in Groot et al. (2014) or Matano and Naticchioni (2012, 2016), is composed of studies where spatial references in empirical analyses tend to be rather small (i.e. municipalities or local labor markets). The high number of spatial references considered in these studies allows the development of econometric analyses that examine the effect of different spatial characteristics (such as amenities or agglomeration economies) on previously estimated spatial fixed effects. The second strand of this literature consists of studies where the geographical references in the empirical analyses are much broader (usually corresponding to NUTS-2 regions), with a comparatively low labor mobility between regions. Their basic purpose is to identify interregional wage differences net of composition effects for observationally similar individuals through the use of econometric decomposition techniques, and the most outstanding references are the seminal studies by Blackaby and Manning (1990, 1995), and subsequent analyses by Motellón et al. (2011) and Pereira and Galego (2011, 2014). 
This article examines regional wage differences in Spain in the period 2006-2014 for NUTS-2 regions, so it fits in the second strand of the literature previously mentioned. Given that in economic spatial research the scale of the regional classification chosen should correspond to the level of aggregation at which the researched phenomenon is expected to operate (Briant, Combes, \& Lafourcade, 2010), we consider that the regional classification chosen to examine wage differentials in the specific case of Spain is particularly adequate to carry out our analysis for different reasons. First, because Spain is a highly decentralized country where many policies are in general designed and implemented at this regional level. Second, because at this regional scale certain labor institutions with influence on wage determination, such as collective bargaining, have a predominant role, and interregional mobility of workers in Spain is particularly low from an international perspective.

Spain is a particularly interesting case for the analysis of interregional wage differences for a number of reasons. The first one regards to the specific characteristics of Spain's labor market institutional framework related to wage determination, and the subsequent important regional disparities observed in the labor market in the country. In particular, collective bargaining in Spain differs to a great extent from other European countries where there exist also a predominance of sectoral agreements and a high coverage rate (between $80 \%$ and $90 \%$ of employees in the Spanish case), given that Spain is the only European country where sectoral collective agreements affect specific regions (NUTS-2 units) or provinces (NUTS-3 units) (Du Caju, Gautier, Momferatou \& Ward-Warmedinger, 2008), and the bulk of workers in the country are actually covered by this type of collective agreements. This allows for very significant and time-persistent regional differences in bargained wage floors agreed in sub-national sectoral collective agreements, which lead to persistent regional wage differentials (Simón et al., 2006). In this vein, available evidence based on harmonized microdata strictly comparable across countries suggests that wage differentials between regions are comparatively high in Spain relative to other European countries where collective bargaining does not have a regional dimension (Simón \& Russell, 2005), a finding which is consistent with previous international evidence that suggests that the specific characteristics of collective bargaining in a country influence significantly wage differentiation between regions (Vamvakidis, 2008). Moreover, it 
is important to note that a strong regional segmentation is observed in the Spanish labor market (International Monetary Fund, 2015; Bover \& Velilla, 2005; Bentolila \& Jimeno, 1998), where, for example, significant and persistent differences in regional employment and unemployment rates are observed (OECD, 2014a, Bentolila \& Jimeno, 1998; Bande, Fernández \& Montuenga, 2008). Some of the main causes behind that segmentation are actually the lack of adjustment in practice of regional wage differentials to regional economic conditions (International Monetary Fund, 2015), and the very low interregional migration flows, among the lowest of all advanced countries, and decreasing after the Great Recession (Bell, 2015; Eurostat, 2015; Liu, 2018).

The second reason to analyze the Spanish case is that during the period examined (2006-2014) there were profound cyclical and regulatory changes, so it is a matter of particular interest to examine the extent to which regional wage differentials are persistent over time despite intense regulatory changes and cyclical fluctuations. In this vein, there were firstly profound regulatory changes in the labor market, most notably through the intense labor reform approved in 2012. As a consequence, greater flexibility in wage determination was introduced modifying inter alia many relevant aspects of collective bargaining (for more details see OECD, 2014b), with subsequent significant changes in the overall functioning of the Spanish labor market (Bank of Spain, 2016; European Commission, 2016). Although regional wages seem to respond still weakly to specific variations in regional economic conditions (International Monetary Fund, 2015), these intense regulatory changes might otherwise be plausibly associated with significant changes in the regional wage structures. On the other hand, in the period examined there were also intense cyclical fluctuations in the Spanish economy due to the effects of the double-dip recession associated with the Great Recession and the crisis in the Euro area, and the subsequent economic expansion (i.e. the unemployment rate before the Great Recession was 8 percent, reached a maximum of 26 percent during the crisis, and at the end of 2018 was around 14 percent, with youth unemployment rates following a similar evolution but more than doubling these figures). 
The empirical analysis of regional wage differences in Spain is carried out using matched employer-employee microdata from the Encuesta de Estructura Salarial, a database that provides rich information on employees and their jobs and firms. Moreover, it is based on econometric decomposition techniques which provide a detailed breakdown of wage differences between regions based on the individual contribution of each subset of explanatory factors, which allow to differentiate in practice between the influence of regional differences in labor forces and in the characteristics of firms in shaping regional wage differentials. The analysis is developed for both regional differences in average wages and for differences observed along the wage distribution. This contrasts with the bulk of the related literature, as only a few of the most recent studies focus on analysis throughout the distribution (as far as we know, they are limited to Motellón et al., 2011; Galego \& Pereira, 2014; and Pereira \& Galego, 2014). Examining what happens along the wage distribution could be especially relevant in the Spanish context, because wage moderation policies adopted during the recent economic crisis are known to have had a heterogeneous effect (with a greater impact on low-wage earners), which could result in changes in regional wage differentials in the lower part of the distribution.

Other relevant aspect of our research is that it extends previous studies on the topic, given that regional differences in purchasing power parities are appropriately controlled for in the estimation of regional wage differentials. This is an issue that has not been properly considered in previous studies regarding this type of differentials in large regions, due to important error measurements in regional parities (Motellón et al., 2011) or to the use of regional inflation in rather short periods to approximate price levels (Galego \& Pereira, 2014; Pereira \& Galego, 2014). This question could be particularly important in the Spanish context given that persistent regional differences in consumer prices are facilitated by a wide dispersion of barriers to entry for firms in the retail sector across Spanish regions (Hoffmaister, 2010). Moreover, to restore external competitiveness and facilitate the adjustment of external imbalances, Spain adopted after the Great Recession an internal devaluation strategy to lower relative wages and prices (Bank of Spain, 2015; Rosnick \& Weisbrot, 2015; Engler \& Klein, 2017). As a consequence, asymmetries across regions 
could emerge as a result of a potential asymmetric pass-through of wage moderation policies into domestic prices in Spanish regions, given their significant differences in terms of productive specialisation and openness (Cuadrado-Roura \& Maroto, 2016), as well as from different effects of the crisis and subsequent economic policies (Groot et al., 2011, Decressin et al., 2015; Agnello, Fazio \& Sousa, 2016).

The article is organized as follows. The next section summarises the literature on regional wage differentials. The third and fourth sections present the methodology and data used in the empirical analysis. The fifth section presents and discusses the empirical evidence, and, last, the final section provides the main conclusions and a discussion of the results.

\section{LITERATURE REVIEW}

According to the seminal paper of Combes et al. (2008) and the subsequent literature (see, for instance, Groot et al., 2014), there are three main causes of interregional wage differentials: differences in productive characteristics, differences in nonhuman endowments, and agglomeration economies. Differences in productive characteristics are related to composition effects. Hence, interregional wage disparities can arise as individuals and firms are spatially sorted in a nonhomogeneous way. Labor force characteristics, such as education or experience, and firm and job requirements could notably vary across regions. Thus, wages in regions with highly educated workers and industries demanding a more favourable skill composition tend to be higher, as wages are linked to productivity. The second reason is related to interregional disparities in amenities, such as climate, institutions, technology, or transportation, as more favourably endowed areas are likely to embrace more productive firms and workers. The third reason for interregional wage differences are agglomeration externalities arising from labor market interactions, connections among firms, and/or knowledge spillovers. In dense areas a better matching between workers' skills and firm requirements can take place, and physical proximity—-together with demand and supply scale effects—allow for reduced input and output transaction costs (Duranton \& Puga, 2004). As a consequence, interregional 
wage differences can also occur, as firms in more concentrated areas can take advantage of those productivity gains.

Broadly speaking, the literature on spatial wage differentials can be divided into two main strands. The first strand of the literature comprises analysis focused in the analysis of wage differentials for small spatial units (namely, cities, metropolitan areas, local labor markets or municipalities), assuming spatial equilibria in a context of free mobility of labor and homogeneous workers where their utility is equalized across space, and therefore the observed wage gap is the result of differences in amenities and/or agglomeration economies (the seminal study in this vein is Combes et al., 2008, and other examples are Groot et al., 2014 and Matano \& Natichionni, 2012, 2016). The second strand, where our article fits, encompasses a second group of studies that examine geographical wage differences for larger regions (usually NUTS-2 units), characterized by low interregional mobility flows (e.g. Motellón et al., 2011; Galego \& Pereira, 2014; and Pereira \& Galego, 2014).

The use of microdata is a common characteristic of most of the studies on spatial wage differentials, as it is important to control for workers' heterogeneity because sorting could determine an important part of regional wage inequalities. In order to deal with this issue, Combes et al (2008) apply a two-stage procedure where they first regress wages of workers as a function of observed characteristics of the individuals, industries and regions where they work adding also different types of fixed effects to control for unobserved heterogeneity. The estimated coefficients for area-year fixed effects are then used in a second-stage equation to assess the relative importance of endowments and between-industry interactions to explain spatial wage differences. While several posterior studies focused on the analysis of spatial wage differentials between small spatial units have followed a rather similar approach (i.e. Groot et al., 2014 and Matano \& Natichionni, 2012, 2016), those studies focused in larger regions, where the number of geographical units is not large enough to apply the two-stage procedure proposed by Combes et al (2008), have applied a different methodological approach based on the use of econometric decomposition techniques. In particular, a 
number of studies have applied the Oaxaca (1973) and Blinder (1973) proposal (OB) to assess the extent to which average regional wage differentials are due either to differences in regional endowments or to differences by region in the returns paid to these endowments. Some examples of studies within this group are Blackaby and Manning (1990, 1995), Vieira et al., (2006) and Pereira and Galego (2011). They conclude that, although different wages are finally paid to similar employees with similar jobs in different regions, it is differences in occupational, industrial, and education structures that play a major role on the explanation of regional wage disparities in countries like Britain or Portugal. ${ }^{\mathrm{i}}$

An aspect that has recently captured the attention of researchers is the analysis of spatial wage differences along the wage distribution and not only for average wages. For instance, in the abovementioned first strand of the literature, focused on the analysis of small spatial units, Matano and Natichioni (2012) examine the relation between spatial externalities (in terms of industrial specialization and density) and wages along the wage distribution for Italian (NUTS-3) provinces. They find that, even after controlling for spatial sorting and endogeneity, there is an increasing impact of spatial externalities along the wage distribution, so it is the skilled workers who benefit most from spatial externalities. In the same vein, Matano and Natichioni (2016), in a disaggregated analysis distinguishing between stayers and migrants, confirm for the Italian case that skilled workers have a greater advantage in wages as a result of working in areas of high employment density. Hakansson and Isacsson (2018) also examine for Sweden the spatial extent of agglomeration economies (through total employment in the area) across the wage distribution, on the basis that the spatial extent of agglomeration benefits could be larger for high- wage earners, spatially more mobile individuals. After controlling for observable and unobservable individual and establishment characteristics and endogeneity, they find that agglomeration economies do not shift the wage earnings distribution in a symmetric way, so the positive effects of increasing economic mass tend to be higher for the upper half of the wage earnings distribution (very especially in economically small locations). 
In the second strand of the literature, spatial wage differentials observed along the wage distribution for large regions have been in turn examined through decomposition techniques that extend the Oaxaca-Blinder approach to different points of the distribution. The number of studies is in general very scarce as, to the best of our knowledge, only Motellón et al. (2011), Pereira and Galego (2014), and Galego and Pereira (2014) have decomposed regional wage differences across the whole wage distribution. The former applies a non-parametric method suggested by Di Nardo, Fortin and Lemieux (2006) and Butcher and Di Nardo (2002), documenting increasing regional wage differentials along the wage distribution for the case of Spain. In turn, Pereira and Galego (2014) follow a semi-parametric method suggested by Machado and Mata (2005) and Melly (2005, 2006), providing evidence on significant interregional wage differentials in Portugal that increase monotonically for men and decrease at the top of the wage distribution in some areas for women. Although the results provided by Motellón et al. (2011) and by Pereira and Galego (2014) detail which part of the wage differential along the wage distribution is due to regional differences in endowments of observable characteristics and which part is due to regional differences in the returns paid to these endowments, none of them shed light on which specific variable(s) most matter in the explanation of interregional wage differentials. By contrast, Galego and Pereira (2014) apply the Fortin, Lemieux and Firpo (2011) proposal, which allows for gauging the contribution of each explanatory variable considered in the wage equation on both the endowment and the return components along the entire wage distribution. In line with the results provided by Pereira and Galego (2011) for interregional wage differentials at the mean in Portugal, Galego and Pereira (2014) conclude that differences in endowments in education, occupation, and firm size explain a relevant part of interregional wage differentials, although in a manner far from constant along the wage distribution.

A final question to note is that studies focusing on wage differentials between large regions, such as our research, are typically based on cross-sections of matched employer-employee data and, as a result, unobserved individual heterogeneity cannot be properly controlled for due to the limitations of the data. Evidence on this question actually suggests that controlling for worker fixedeffects is important and that, hence, sorting of workers is very relevant in explaining inter-area wage 
differentials (Combes et al., 2008) or in relation to the impact of agglomeration economies in wages from a spatial perspective (Matano \& Natichioni, 2012). Yet, controlling in wage equations for occupations, as it is the case in our analysis, could partially correct for possible spatial selection biases as it may capture unobserved ability components (Duranton \& Monastiriotis, 2002).

Taking all this into account, our article extends the previous literature by analyzing spatial wage differentials in large regions after properly controlling for regional differences in purchasing power parities and applying decomposition techniques that properly allow to consider the role of individual, work and firms characteristics in explaining wage differentials observed both in average wages and along the wage distribution.

\section{METHODOLOGY}

Our empirical approach to the analysis of interregional wage differentials in Spain consists of the decomposition of regional differences in wages to ascertain the extent to which they are explained by regional endowments of the characteristics of labor forces and firms or, alternatively, by the presence of adjusted regional differentials nets of composition effects. To decompose differences in averages and quantiles along the wage distribution we use the standard Oaxaca (1973) and Blinder (1973) methodology and the extension to this technique proposed by Fortin et al. (2011) based on the use of the recentered influence function (RIF) and the estimation of unconditional quantile regressions (Firpo, Fortin \& Lemieux, 2009), respectively. It must be noted that unlike related techniques (i.e., Juhn, Murphy \& Pierce, 1993; Machado \& Mata, 2005), this methodology provides detailed evidence on the effect of individual explanatory variables on wage differentials that is not path-dependent (for details, see Fortin et al., 2011).

3.1. Decomposition of regional differences in average wages: The Oaxaca-Blinder methodology

The Oaxaca-Blinder decomposition is formulated to decompose mean differences in wages between two groups (in our case the comparison is made between each region and the whole country) after the estimation of a semi-logarithmic wage equation, as 


$$
w_{i r}=X_{i r} \beta_{r}+\varepsilon_{i r}
$$

wherein $w_{i r}$ denotes the log of hourly wage of individual $\mathrm{i}$ in region $r, X_{i r}$ is a vector of controls including characteristics of individuals and their jobs and firms; $\beta_{r}$ is a vector of returns to observed characteristics in region $r$ (including an intercept); and $\varepsilon_{i r}$ is a stochastic error term.

To decompose mean differences in wages between region $r$ and the national average, after having estimated a non-discriminatory reference wage structure with the pool of the two geographical references involved in the comparison, ${ }^{\text {iii }}$ based on the properties of the ordinary least square estimator, the difference in average wages between the region and the whole country may be broken down as follows

$$
\begin{aligned}
& \hat{\Delta}_{O}^{\text {average }}=\left(\bar{w}_{r}-\bar{w}_{S}\right)=\left(\bar{X}_{r}-\bar{X}_{S}\right) \hat{\beta}^{*}+\left\{\bar{X}_{r}\left(\hat{\beta}_{S}-\hat{\beta}^{*}\right)+\bar{X}_{S}\left(\hat{\beta}^{*}-\hat{\beta}_{r}\right)\right\} \\
& =\quad \hat{\Delta}_{X}^{\text {average }}+\hat{\Delta}_{S}^{\text {average }}
\end{aligned}
$$

wherein $\bar{w}_{r}$ and $\bar{w}_{S}$ are the average wages of the region $r$ and Spain; $\bar{X}_{r}$ and $\bar{X}_{S}$ are the average observed characteristics of individuals and firms of region $r$ and the whole country (comprising gender, age, education, nationality, tenure, type of contract, full- or part-time, supervisory tasks, occupation, sector, size, type of collective agreement, type of control, type of market, the proportion of women and immigrants in the firm, the proportion of workers with fixed-term and with part-time contracts, the proportion of workers employed in unskilled and skilled occupations in the firm, and the proportion of workers with primary and tertiary education in the firm); and $\hat{\beta}_{r}, \hat{\beta}_{S}$ and $\hat{\beta}^{*}$ are the estimated coefficients following regression of wages on the set of explanatory variables for the region, the country, and the pool of both geographical references, respectively. The term $\hat{\Delta}_{X}^{\text {average }}$ is the composition effect, reflecting the part of the average raw wage differential between region $r$ and the whole country arising from differences in endowments of characteristics, whereas the 
term $\hat{\Delta}_{S}^{\text {average }}$ is the wage structure effect, which corresponds to differences in the wage structure, and captures the regional differential net of composition effects.

3.2. Decomposition of regional differences across the wage distribution: The Fortin-Lemieux-Firpo methodology

The Fortin et al. (2011) methodology is an extension of the standard Oaxaca-Blinder decomposition that provides detailed decompositions of differences in any distributional statistic, such as the quantiles. The technique is based on the estimation of a regression in which the independent variable (the wage) is substituted by a transformation of the same, the recentered influence function (RIF). The influence function measures the effect on distributional statistics of small changes in the underlying distribution. Thus, for a given distributional statistic of the distribution $F_{W}, v(F)$, this function measures the importance of each observation in shaping the value of the statistic. Fortin, Lemieux, and Firpo (2011) suggest using a recentered version of the influence function adding the statistic of interest, $R I F(W)=v(F)+I F(W)$, since its expected value is the actual statistic $v(F)$ (insofar as the expectation of the function of influence with respect to distribution of $W$ is, by definition, zero).

In the case of the quantiles $q_{\tau}$ of the unconditional marginal distribution $F_{W}$, the recenteredrecentered influence function, $\operatorname{RIF}\left(w, q_{\tau}\right)$, is defined as follows

$$
\operatorname{RIF}\left(w / q_{\tau}\right)=q_{\tau}+\frac{\tau-l\left\{W<q_{\tau}\right\}}{f_{W}\left(q_{\tau}\right)}
$$

where $l\{\cdot\}$ is an indicator function and $f_{W}$ is the function of density of the marginal distribution of $w$ evaluated in $q_{\tau}$. The RIF may be computed empirically in the case of the quantiles by means of a local inversion following calculation of the dummy variable $l\left\{w<q_{\tau}\right\}$ (which specifies whether the value $w$ is higher or lower than $q_{\tau}$ ), the estimation of the quantile of the sample $q_{\tau}$, and 
the estimation by means of kernel density functions of the corresponding density function $f_{W}$ evaluated in $q_{\tau}$.

Following the calculation of the RIF for the quantile, a value is provided for the transformed variable for each observation of the sample. Insofar as the effect of the change in distribution of an explanatory variable in the quantile may be expressed ceteris paribus, as the average partial effect of that variable in the conditional expectation on its RIF, and assuming that the conditioned expectation of the RIF may be modelled as a linear function of the explanatory variables, these values may be used for estimation by ordinary least squares of a regression of the RIF variable in a vector of explanatory variables. The estimated coefficients may be interpreted as the partial effect of an increase in the average value of an explanatory variable in the distribution quantile (Firpo et al., 2009), so that subsequently a standard Oaxaca-Blinder decomposition, as expressed in equation (2), can be developed for the quantiles of the wage distribution based on the regression results.

However, that decomposition would yield consistent results only if the true conditional expectation of the RIF could be modelled as a linear function of the explanatory variables, implying that decomposition results based on linear regressions may be biased (Barsky, Bound, Charles \& Lupton, 2002). For that reason, Fortin et al. (2011) recommend a two-step procedure to carry out the decomposition. The first step consists of following the Di Nardo et al. (1996) reweighting procedure to account for potential non-linearities in the true conditional expectation of the RIF. ${ }^{\text {iv }}$ This reweighting procedure generates counterfactual observations that would result if individuals in the whole country had the same distribution of observable characteristics as individuals in region $r$, and it is based on the weights estimated via a probit model on the probability of being observed in region $r{ }^{\mathrm{v}}$ Having estimated the RIF regressions for workers in region $r$, the whole country, and the counterfactual wage distribution on the reweighted sample, in a second step a Oaxaca-Blinder-type decomposition analysis can be performed on the reweighted data for any unconditional quantile $(\tau)$ of the wage distribution 


$$
\begin{aligned}
& \hat{\Delta}_{O}^{\tau}=\left(\bar{X}_{r} \hat{\beta}_{\tau, r}-\bar{X}_{S}^{C} \hat{\beta}_{\tau, S}^{C}\right)+\left(\bar{X}_{S}^{C} \hat{\beta}_{\tau, r}^{C}-\bar{X}_{S} \hat{\beta}_{\tau, S}\right) \\
& =\quad \hat{\Delta}_{S}^{\tau}+\hat{\Delta}_{X}^{\tau}
\end{aligned}
$$

where superscript $\mathrm{C}$ stands for the reweighted sample estimates; $\bar{X}_{r}$ and $\bar{X}_{s}$ are the covariates means in region $r$ and the whole country; $\hat{\Delta}_{S}^{\tau}$ is the wage structure effect; and $\hat{\Delta}_{X}^{\tau}$ is the composition effect.

The wage structure effect can be further decomposed as:

$$
\begin{aligned}
& \hat{\Delta}_{S}^{\tau}=\bar{X}_{r}\left(\hat{\beta}_{\tau, r}-\hat{\beta}_{\tau, S}^{C}\right)+\left(\bar{X}_{r}-\bar{X}_{S}^{C}\right) \hat{\beta}_{\tau, S} \\
& =\hat{\Delta}_{S, p}^{\tau}+\hat{\Delta}_{S, e}^{\tau}
\end{aligned}
$$

where $\hat{\Delta}_{S, p}^{\tau}$ is the pure wage structure effect, which provides the part of the wage differential explained by differences in the returns to observed characteristics at quantile $\tau$ and results from the difference between $\hat{\beta}_{\tau, r}$ and $\hat{\beta}_{\tau, S}^{C}$, and $\hat{\Delta}_{S, e}^{\tau}$ is the reweighting error, reflecting the fact that the reweighted sample average $\bar{X}_{s}^{C}$ may be different from $\bar{X}_{r}$.

In a similar way, the composition effect can be expressed as

$$
\begin{aligned}
& \hat{\Delta}_{X}^{\tau}=\left(\bar{X}_{S}^{C}-\bar{X}_{S}\right) \hat{\beta}_{\tau, S}+\bar{X}_{S}^{C}\left(\hat{\beta}_{\tau, S}^{C}-\hat{\beta}_{\tau, S}\right) \\
& =\hat{\Delta}_{X, p}^{\tau}+\hat{\Delta}_{X, e}^{\tau}
\end{aligned}
$$

where $\hat{\Delta}_{X, p}^{\tau}$ is the pure composition effect, which provides the part of the wage differential explained by differences in the observed characteristics at quantile $\tau$, and $\hat{\Delta}_{X, e}^{\tau}$ is the specification error, which should be zero in cases where the model is linear. ${ }^{\mathrm{v}}$ 


\section{DATA AND VARIABLES}

\subsection{The Encuesta de Estructura Salarial}

The data used in this research come from the Encuesta de Estructura Salarial (Structure of Earnings Survey; hereafter EES), corresponding to 2006, 2010, and 2014. This survey is the equivalent of the sample for Spain of the European Structure of Earnings Survey, a survey conducted in all European Union members with harmonized information on wages. The EES is conducted every four years, providing independent cross-sectional data, currently available in five waves (1995, 2002, 2006, 2010, and 2014) and its information has increased over time in terms of variables and coverage, with the last waves covering firms of any size and most sectors of the economy (the only exceptions are agriculture and a very reduced number of branches of services). The three last waves have been considered in the empirical analysis, as they contain more complete information and cover almost fully the private sector of Spain's economy.

One of the main features of the EES is that it contains matched employer-employee microdata, as its design corresponds to a two-stage sampling of employees holding a job in workplaces registered in the social security system, and includes observations for various employees in each workplace. Consequently, the survey gathers very rich information regarding wage determinants related to both workers and their jobs and workplace characteristics. It is also noteworthy that the EES contains representative, disaggregated information at the regional level, serving as the reference the Spanish 17 autonomous communities/regions, equivalent to NUTS 2 units. As a consequence, regional analysis can be carried out using information about the region in which the workplace is located. ${ }^{\text {vii }}$

The two-stage stratified sampling method applied in the EES guarantees that the samples of employees surveyed are representative of the entire population of workers in each workplace. Thus, the first-stage units (workplaces registered in the social security system) are classified according to their economic activity, with each category stratified by region and size range (eight ranges). Stratum 
sample sizes are then obtained within this stratification with a maximum admissible error of 5 percent, being the survey exhaustive for workplaces with more than 499 workers. Second-stage units (workers) are selected among those working during the entire reference month (October), and sampling depends on the size of the firm, being exhaustive for micro-firms (i.e., those with fewer than 10 workers), up to 25 employees at bigger firms (the average observations per firm in the sample is around 15).

As indicated before, the independent variables considered in the empirical analysis gather rich information regarding both workers and their jobs and workplace characteristics. Worker characteristics variables include gender, nationality (natives vs. immigrants), education level (primary, secondary or higher education), and age (less than 30, 30-45, and more than 45 years old). Job characteristics variables include occupation (nine categories for major occupational groups), years of tenure in the current job and its square, type of contract (permanent or fixed-term), full- or part-time, and the eventual performance of supervisory tasks. Finally, firm characteristic variables include sector (12 categories), size (six strata), type of collective agreement (firm agreement, national sectoral agreement, or subnational sectoral agreement), and a full set of variables regarding the composition of the labor force in the workplace (measuring, respectively, the proportion of women and immigrants in the firm, the proportion of workers with fixed-term contracts and part-time jobs, the proportion of workers performing skilled and unskilled occupations, and the proportion of workers holding primary or tertiary education) as proxies of the quality of the labor force of the workplace and, hence, its productivity (Card \& De la Rica, 2006).

In conducting the empirical analysis, certain individuals are excluded, namely, those under the age of 16 or over the age of 65 , those with hourly wages of more than 200 euros and those living in the autonomous cities of Ceuta and Melilla. In the same vein, in order to use a homogeneous sectoral coverage for all the waves of the survey, observations corresponding to section O of NACE-2009 (Public administration and defence, compulsory social security) have been removed from the 2010 and 2014 waves so that the analysis corresponds to the private sector. The final samples are formed 
by 139,989 employees in $2006,164,266$ in 2010 , and 149,009 in 2014. Regional samples are ample, given that they range between 2,495 and 21,638 employees in 2006, between 2,502 and 29,830 in 2010, and between 2,520 and 28,402 in 2014. The descriptive statistics of the samples are shown in Tables A.1 to A.3 in the Appendix. It must be noted that throughout all the empirical analysis the sample weights provided in the EES have been used.

Results of estimating wage equations may be influenced by selection bias induced by two different potential factors: unobserved differences between employees and non-participants in the labor market and between migrants and non-migrants, and spatially related factors correlated with wages. In our research it is not possible to control for these types of selection bias, given that the dataset includes information only for employees and it does not distinguish whether they are migrants or not. Yet, it is plausible that the results are not greatly affected by selectivity for different reasons. First, because the patterns of labor participation are rather similar across Spain's regions (e.g., in 2014 the average participation rate in Spain was $59.5 \%$ of the total labor force, with a 0.052 coefficient of variation of the regional participation rates), which precludes the existence of significantly different regional labor participation decisions by individuals. Second, because internal migration in Spain is very low (Liu, 2018; International Monetary Fund, 2015; Bover \& Velilla, 2005), so the evidence might not plausibly be significantly affected by migration. On the other hand, given that wage equations include controls for occupations, which may capture unobserved ability components, the analysis could also partially correct for possible spatial selection biases (Duranton \& Monastiriotis, 2002).

\subsection{Regional purchasing power parities}

The dependent variable in our estimations is the gross hourly wage for October-the month that defines the survey population-divided by the number of hours actually worked that month, and additionally adjusted by regional purchasing power parities (PPP). Regional PPP used in the empirical analysis are derived from those provided in Costa, García, López and Raymond (2015). Given the lack of data available at a regional level to directly calculate the corresponding PPP, these authors 
propose the use of an indirect method to calculate these PPP, in the spirit of OECD and Eurostat methodologies. In particular, Costa et al. (2015) estimate Spanish regional PPP on the basis of three different approaches: (i) to update regional PPP available for $1989^{\text {viii }}$ using changes in regional Consumer Price Indexes provided by the National Statistics Institute; (ii) to estimate an equation that relates prices and GDP on the basis of the Balassa (1964) and Samuelson (1964) hypothesis using OECD data at a national level, and then to use the estimated coefficients to obtain regional PPP with regional data; and (iii) to estimate microeconometric models for regional product prices following Coondoo, Majumder and Ray (2004), using household level data on income, household composition, and individual characteristics from the Household Budget Survey for the period 2009-2012. The results obtained with the three methods are consistent, being the regional PPP finally reported by Costa et al. (2015) a weighted average of the PPP derived from methods (ii) and (iii). A similar approach has been used recently in Costa, García, Raymond and Sánchez-Serra (2019) to estimate regional PPP for a large set of OECD countries, including Spain.

The pattern of regional PPP estimated by Costa et al. (2015) is rather similar to alternative available estimations for Spanish regions based on indirect methods by Janský and Kolcunová (2017). In particular, these latter authors use the PPP already available at a regional level for six European Union countries to estimate an equation that relates prices with a full set of economic and demographical variables, and then use the estimated coefficients to proxy PPP for the regions (NUTS-2) of other European Union countries, including Spain. The resulting estimations of the PPP for the Spanish regions in this case are highly correlated with those of Costa et al. (2015), being very similar both in the ordering of the regions and in its dispersion.

To conclude, it must be noted that as the original estimations or regional PPP of Costa et al. (2015) correspond to 2012, to calculate the values for 2006, 2010 and 2014, the change in the value of the Consumer Price Indexes (CPI) of each region between each year and 2012 has been applied (measured in each case from the average of all the months of the year), normalized with respect to the national average. 


\section{RESULTS}

\subsection{Descriptive evidence}

Table 1 and Figure 1 contain purchasing power parities for Spanish regions. As stated before, they correspond to the original estimates of Costa et al. (2015) for 2012 and the subsequent calculations for 2006, 2010 and 2014 using regional changes in the value of the consumer price index. This evidence confirms that there exist very significant differences in price levels across Spanish regions. Hence, prices are significantly higher in certain regions (i.e. prices in Madrid are 15 percent higher than the national average), and significantly lower in other regions (around 15 percent and 20 percent under then national average in the Canary Islands or Extremadura), so that very important differences are found in general, with coefficients of variation around 0.10 and differences of more than $40 \%$ between the regions with the highest and the lowest price levels. Regional differences in price levels are also very persistent over time: correlations between values for different years are close to one, due to the presence of a very important regional homogeneity in inflation patterns.

\section{[INSERT TABLE 1 HERE]}

\section{[INSERT FIGURE 1 HERE]}

Table 2 and Figure 2 show, in turn, the average hourly wages of the Spanish regions in the years examined. Wages are expressed in euros and they correspond to the raw values (left panel of Table 2 and upper panel of Figure 2) and to raw wages deflated by regional purchasing power parities (right panel of Table 2 and lower panel of Figure 2). In short, this information confirms the presence of very significant regional differences in raw average hourly wages, and also that its structure differs significantly when regional purchasing power parities are considered. Thus, without considering purchasing power parities regional wages range between 23 percent above the national average and 28 percent below, they show differences between the maximum and minimum values of around 50 percent in 2006 and 2010 and 72 percent in 2014, and they display a high dispersion according to different inequality measures (the coefficient of variation and the Gini index are between 0.11 and 
0.12 and 0.05 and 0.06 , respectively, depending on the year). However, when regional purchasing power parities are considered, regional differences in wages are more reduced (although they are still significant), with regional average wages varying between 14 percent above and 16 percent below the national average, differences between the regional maximum and minimum values between 20 percent and 31 percent, and inequality measures that are systematically halved (they are also relatively similar across time, with correlations between 0.67 and 0.83 , depending on the years compared). It is also remarkable that, although there is some correspondence between regional wages depending on whether regional differences in prices are controlled for (Figure 3), the correspondence is relatively weak (the coefficients of correlation exhibit values around 0.55 in 2006 and 2014 and 0.35 in 2010 and are statistically significant only in the first two cases, at 5 percent). For example, in the case of Madrid, raw non-deflated wages are around 10-15 percent higher than the national average but wages deflated by regional price levels are actually around the national average. Conversely, in certain regions such as Castilla-La Mancha, Castilla y León or Asturias, where raw non-deflated wages are comparatively low, wages corrected by differences in purchasing parity are among the highest in the country. Hence, this overall evidence reveals that controlling for regional price level differences alters significantly the regional wage structure, both in the magnitude of the differentials observed and in regional wage ordering. Consequently, the rest of the empirical analysis systematically accounts for regional wages controlling for regional purchasing power parities.

[INSERT TABLE 2 HERE]

[INSERT FIGURE 2 HERE]

\section{[INSERT FIGURE 3 HERE]}

Figure 4 and Table 3 show raw regional wages deflated by regional price differences for each of the considered years at different points in the distribution of wages $\left(10^{\text {th }}\right.$ percentile, median, and $90^{\text {th }}$ percentile). Initially, this evidence reveals that there exist significant regional wage differences across the whole wage distribution. Moreover, it shows that there exist certain differences in their 
dispersion across the distribution, with regional differences tending to be larger in the right part (as a matter of example, in 2014 the Gini index in the $10^{\text {th }}$ percentile, the median, and the $90^{\text {th }}$ percentile of the wage distribution is $0.037,0.033$, and 0.045 and the difference between the maximum and the minimum wage is of 31 percent, 31 percent and 48 percent).

\section{[INSERT TABLE 3 HERE]}

\section{[INSERT FIGURE 4 HERE]}

The correspondence between regional wage differences observed in different parts of the distribution is relatively weak. Hence, although there is a certain resemblance between the structure of differentials in the left and central parts of the distribution (where statistically significant positive correlations are observed: Table 4), this similarity tends to be rather weak in the rest of the wage distribution, particularly as regards to the parts of the distribution that are most remote from each other (with non-significant correlations). In this vein, it is illustrative that many of the Spanish regions tend to exhibit wages higher (lower) than national averages in certain parts of the distribution and lower (higher) in other parts (Figure 4). Overall, these findings confirm that significant regional raw wage differentials exist across the wage distribution and that its structure tends to differ among different parts of the distribution. Hence, this evidence underlines the appropriateness of carrying out an analysis of the origin of the regional wage differences throughout the whole wage distribution and not focused exclusively on average wages.

\section{[INSERT TABLE 4 HERE]}

Tables A.1 to A.3 in the Appendix include the descriptive statistics of the explanatory variables in each year (due to space constraints, the information corresponds just to the average of the variables). In general, although there are not significant regional differences in labor force characteristics such as the relative presence of women or the age structure, there are, however, notable differences in certain aspects, such as the relative presence of immigrants (with proportions of employees that, for example, in 2014 range from 2.7 percent in Galicia to 12.7 percent in the 
Balearic Islands) and of individuals with a university education (with a minimum in 2014 of 14.8 percent in the Balearic Islands and a maximum above 40 percent in Madrid and the Basque Country). ${ }^{\text {ix }}$ Similarly, significant differences in the characteristics of jobs and firms are observed, reflecting differences in the characteristics of the productive structure in each region. Thus, in regions such as Madrid and the Basque Country there are occupational structures with a high presence of highly-skilled jobs (directors and managers, technical and scientific professionals, and technicians and associate professionals); sectoral structures associated with high wages (like manufacturing in the case of the Basque Country); a greater presence of firms with their own collective agreements; and more qualified labor forces inside firms (in Madrid there is also a lower incidence of fixed-term jobs and a much greater presence of larger companies). On the contrary, in other regions such as the Balearic Islands or Extremadura there are high incidences of fixed-term jobs; occupational structures with fewer highly-skilled jobs; sectoral structures associated with low wages; firms with smaller sizes and without their own collective agreements; and less qualified workers inside firms. In a nutshell, this evidence confirms the presence of significant regional differences in the characteristics of workers, jobs and firms. The rest of the analysis examines to what extent regional wages differentials are explained by these regional differences observed in labor forces and productive structures or if, on the contrary, they cannot be fully explained by such differences in endowments.

\subsection{Decomposition of inter-regional average wage differences}

Figure 5 shows the results of the decomposition of regional differences in average wages in the period examined using the Oaxaca-Blinder methodology (full results of the decomposition can be found in Table A.4 in the Appendix). As indicated in the methodology section, in order to make an homogeneous comparison for all regions, throughout all the empirical analysis the reference in the comparison for each region is the whole Spanish economy. As also indicated before, the specification of the wage equation (1) used in the empirical analysis includes a broad set of explanatory variables, grouped into (i) socio-demographic characteristics of individuals that measure the attributes of the labor force in the region (gender, nationality, age, and education) and (ii) firm characteristics that 
proxy the characteristics of the regional economic structure (job and workplace attributes such as tenure, type of contract, full- or part-time, supervisory tasks, occupation, sector, size, type of collective agreement, and several characteristics of the workplace's workforce comprising the proportion of women and immigrants in the firm, the proportions of workers with fixed-term and with part-time contracts, the proportion of workers in unskilled and skilled occupations, and the proportion of workers with primary and tertiary degrees).

\section{[INSERT FIGURE 5 HERE]}

As noted in the methodology section, the results of the decomposition are calculated taking into account the possible presence of errors in the estimation of both the characteristics and returns components via the additional use of the Di Nardo et al. (1996) reweighting procedure. As a consequence, the difference in the average wage of each region with respect to the national average is decomposed according to the four components in equations (3) and (4): the pure component of characteristics (that can be detailed in this case into the effect of differences in the endowments of individual characteristics, and of jobs and companies, respectively); the error term estimated in the characteristic component; the error term estimated in the returns component; and the pure returns component. This latter component is of particular interest, given that it captures wage differentials for employees with similar attributes and working in similar jobs and firms and, consequently, quantifies the estimated adjusted regional wage differentials net of composition effects.

The evidence obtained using the decomposition technique (Figure 5 and table A.4 in the Appendix) shows, on one hand, that a significant part of regional wage deviations from the national average is due to composition effects captured by the pure effect of regional differences in observed characteristics, and that in some cases controlling for the specificities of the labor force and the productive structure of the region alters its relative wage, on the other. As a matter of example, the results of the decomposition show that the lower-than-average raw wage that exhibit the Balearic Islands in every year is explained by the worse characteristics of workers and firms in the region relative to the whole Spanish economy (plausibly due to the higher relevance of tourism in the 
region), and that once these worse endowments are taken into account employees in the region actually earn wages with a higher purchasing power than workers with similar characteristics and working in similar firms in the rest of Spain. Moreover, the results of the detailed decomposition, which allow to differentiate between the effect of differences in characteristics of individuals and jobs and firms, show that these composition effects are due very especially to regional specificities in terms of productive structures and only to a much lesser extent to differences in labor forces. Hence, for instance, in 2006 the characteristics of jobs and firms were related with wages 7 percent higher than the national average in Madrid and the Basque Country and between 7 percent and 8 percent lower in Extremadura and Asturias, while in all four cases the particularities of the regional labor forces had a negligible effect on the relative wages of those regions.

On the other hand, the term that corresponds to the pure effect of the returns component, which captures adjusted regional wage differentials, presents in general a high explanatory power. Hence, this term shows that similar employees working in similar jobs and firms earn hourly wages that vary in practice in the range between 10 percent lower and 10 percent higher than the national average (in Madrid and several regions, depending on the year, respectively). Overall, this evidence confirms that in the Spanish labor market there exist very significant adjusted regional differences in average wages, net of composition effects. Moreover, it also shows that, as is apparent in Figure 5, these differentials 'unexplained' by regional differences in labor forces and economic structures are strongly persistent over time, with a pattern that is generally very similar for all years examined (correlations between the values of regional unexplained components for different years are actually higher than 0.9 in every case, which contrasts with comparatively lower correlations previously observed for average raw wages). ${ }^{x}$

To conclude, it should be noted that the error terms estimated in the components of characteristics and returns tend to be very small in all cases, and therefore have a negligible effect in general, implying that the pure components of characteristics and returns explain almost all regional wage differences observed in practice. 
5.3. Decomposition of inter-regional wage differences across the wage distribution

Figures 6 to 8 (and Tables A.4 to A.6 in the Appendix in the case of full results) present the results of the decomposition between the wages of each region and those of Spain at different points in the wage distribution (the $10^{\text {th }}$ percentile, the median, and the $90^{\text {th }}$ percentile). Starting with the lower part of the wage distribution (Figure 6), the main finding is that wage differences associated with composition effects are generally very small (in many case the estimated effects are negligible: upper panels of Tables A.5 to A.7), so that the bulk of regional wage differences observed in that part of the wage distribution are adjusted differentials net of composition effects captured by the pure component of returns (note that the estimated error term in both the components of characteristics and returns are again generally very small).

\section{[INSERT FIGURE 6 HERE]}

In contrast, regional wage differences observed in the central part of the distribution (Figure 7) are explained both by the presence of net adjusted differentials and by a significant influence of composition effects (as in the case of average wages, this impact is also especially associated with regional differences in job and firm characteristics, and not so much to differences in the characteristics labor forces). This same pattern is also observed in the upper part of the distribution (Figure 8), although in this case with a much more important influence of composition effects (due again mainly to regional differences existing in job and firm characteristics). For illustrative purposes, in 2014 the composition effect related to job and firm characteristics had average and maximum impacts (measured in absolute values) on regional wages of 0.080 and 0.214 log points in the $90^{\text {th }}$ percentile of the wage distribution, of 0.044 and $0.104 \log$ points in the median, and of just 0.013 and $0.043 \log$ points in the 10 th percentile of the wage distribution. In the case of regional differences in the characteristics of the labor force these effects were in all cases significantly lower, with average and maximum impacts of 0.003 and $0.012 \mathrm{log}$ points in the $10^{\text {th }}$ percentile, 0.005 and $0.016 \log$ points in the median, and 0.011 and $0.028 \log$ points in the 90 th percentile of the wage distribution. 
In any case, one of the main findings of this part of the analysis is that noteworthy adjusted regional wage differentials (captured by the pure wage structure component) exist all along the wage distribution. This is apparent, for instance, in the high standard deviation of unexplained components of regional wages in all parts of the wage distribution (Table 5). Another remarkable result is that these adjusted regional wage differentials exhibit a profile relatively similar both across different points of the wage distribution and over time. Thus, in the first case unexplained components of regional wages estimated in different percentiles of the wage distribution unveil very high, significant correlations even when comparing the most distant parts of the wage distribution (Table 6), which contrasts with the weaker correspondence previously observed in regional differences in raw wages (Table 4). Similarly, regions with higher (lower) than national unexplained components of regional wages in some parts of the wage distribution tend to exhibit comparatively higher (lower) magnitudes of those components in the rest of the distribution (Figure 9), in contrast again with the pattern observed in raw wages (Figure 4). In the same vein, the pattern of unexplained components of regional wages estimated in the same part of the wage distribution exhibits very strong similarities over time, very especially for those in the lower part of the wage distribution (Table 7). Overall, this evidence suggests that adjusted regional wage differentials net of composition effects have a relatively similar profile across the wage distribution and over time, which suggests the presence of common forces that affect the wages of all the workers in each region and that are rather stable over time.

\section{CONCLUSIONS}

This article examines wage differences among the Spanish regions in the period between 2006 and 2014. Spain is a particularly interesting case of analysis for this type of differentials because previous evidence suggests that the country exhibits important wage differences between regions from an international perspective, in whose origin labor institutional elements related to the particularities of 
collective bargaining seem to play a relevant role. In the same vein, the Spanish labor market experienced profound cyclical and regulatory changes during the period analyzed, which permits to examine the extent to which differences between regions tend to persist over time even in very different scenarios.

One of the main novelties of the research is that, unlike previous related studies, differences in regional purchasing power parities are controlled for in the estimation of inter-regional wage differences, on the basis of the recent estimations of regional parities Costa et al. (2015, 2019). This is noteworthy, as regional differences in price levels are very significant in practice in Spain (with differences in price levels in a range higher than 40 percent) and persistent over time, and, controlling for them leads to significant alterations in the structure of regional wage differentials. Consequently, the consideration of regional purchasing power parities proves to be particularly relevant and allows to provide novel evidence on the topic, complementary to that obtained in previous related studies where regional differences in prices were not properly considered.

The empirical analysis is based on cross-section matched employer-employee microdata with a wealth of information about wage determinants related to the characteristics of employees and their jobs and firms. The use of this type of microdata, combined with the econometric decomposition techniques of Oaxaca-Blinder and Fortin-Lemieux-Firpo, allows to examine the importance in the generation of wage differences between regions of the composition effects associated with differences in the characteristics of labor forces and firms, on one hand, and of adjusted, net of composition effects interregional wage differentials, on the other hand. Our analysis of the origin of regional wage differences covers both average wages and differences observed across different parts of the wage distribution, in line with the most recent studies on this topic.

The evidence obtained shows firstly that controlling for regional purchasing power parities is very important when estimating regional wage differences, given that in the Spanish case it reduces their dispersion and alters the ordering of the regions significantly. The results of the econometric decompositions confirm, in turn, that a part of the very significant raw regional wage differences 
observed in Spain both in average wages and across the wage distribution are explained by composition effects. Thanks to the use of a rich set of matched employer-employee data and detailed econometric decompositions, it is observed that these effects are explained very especially by regional differences in productive structures, and just partially by differences in labor forces. Moreover, composition effects are also very different across the wage distribution, being particularly weak when comparing lower wages and especially relevant when comparing higher wages, giving rise to patterns of raw regional differences which are not fully coincident along the wage distribution. In the same vein, the evidence obtained confirms that very significant adjusted regional differences net of composition effects remain after controlling for the rich set of individual and firm characteristics considered. In contrast with what is observed in raw wages, these unexplained differentials are rather similar throughout the wage distribution. Moreover, they are strongly persistent over time, which is striking despite the very intense changes that occurred in Spain during the period examined both in the economic cycle and in labor regulations regarding wage determination.

This overall evidence that in Spain there exist significant regional wage differences net of composition effects, and that they are very similar throughout the wage distribution, showing a strong temporal persistence in very different cyclical and regulatory labor scenarios, suggests the presence of common mechanisms in the generation of regional wage differentials that affect the whole labor force and that are strongly persistent over time. Given that in Spain collective bargaining exhibits both a high coverage and an important time inertia in wage determination, and given also that sectoral agreements have an unusual regional dimension, this evidence is consistent with a role of collective bargaining in the generation of regional differences and, consequently, with a potential role of noncompetitive factors in the origin of wage differences between regions in Spain. This finding is actually in line with available international evidence suggesting that the characteristics of collective bargaining in each country influence significantly wage differentiation between regions (Vamvakidis, 2008).

In this vein, considering that regional wage differences do not appear to be due to compensatory factors (Galego \& Pereira, 2014; Simón et al., 2006) or to temporary disequilibrium 
situations, given the strong temporal persistence observed here for this type of differentials (see also Pereira \& Galego, 2011 for Portugal), the main usual hypotheses about their origin focus on competitive factors related to sorting effects of workers and agglomeration economies that could increase productivity and wages (e.g. Combes et al., 2008 and Pereira \& Galego, 2014). Although in the specific case of Spain a very low inter-regional mobility is expected to reduce the potential relevance of sorting effects, and the unequal impacts of both sorting and agglomeration effects observed along the wage distribution (Hakansson \& Isacsson, 2018, for Sweden and Matano \& Natichioni, 2012, 2016, for Italy) is at odds with the similarity observed in unexplained regional differences throughout the wage distribution in Spain, persistent wage differences among Spanish regions could be plausibly explained by agglomeration economies and/or sorting effects, very especially considering that unobserved individual heterogeneity cannot be properly controlled for due to the limitations of our cross-section data. Anyway, the evidence obtained for the Spanish case suggests, in a complementary manner, that very significant, time persistent, very similar across the wage distribution wage differentials for observationally similar workers could be favoured by a specific configuration of collective bargaining, and, hence, that institutional non-competitive elements might also play a role in shaping interregional wage differentials. In any case, further research is warranted in order to provide a deeper and better understanding of the potential link between institutional labor characteristics and regional wage differentials.

\section{Acknowlegments}

This work was supported by the Spanish Ministry of Science, Innovation and Universities (Agencia Estatal de Investigación), the European Union (ERDF) and the Junta de Extremadura [grant numbers CSO2017-86474-R, ECO2014-53702-P and ECO2016-75805-R, National Plan for Research, Development and Innovation, Spain, and GR18106]. 


\section{REFERENCES}

Agnello, L., Fazio, G., \& Sousa, R. M. (2016). National fiscal consolidations and regional inequality in Europe. Cambridge Journal of Regions, Economy and Society, 9 (1). 59-80.

Bande, R., Fernández, M. \& Montuenga, V. (2008). Regional unemployment is Spain: disparities, business cycle and wage setting. Labour Economics, 15(5), 885-914.

Bank of Spain (2015). Competitive adjustment and recovery in the Spanish economy. Annual Report 2014.

Bank of Spain (2016). Annual report 2015.

Balassa, B. (1964). The purchasing power parity doctrine: A reappraisal. Journal of Political Economy, 72, 584-596.

Barsky, R., Bound, J., Charles, K. \& Lupton, J. (2002). Accounting for the black-white wealth gap: a nonparametric approach. Journal of the American Statistical Association, 97, 663-673.

Bell (2015). Internal Migration and Development: Comparing Migration Intensities Around the World. Population and Development Review, 41(1), 33-58.

Bentolila, S. \& Jimeno, J.F. (1998). Regional unemployment persistence (Spain, 1976-1994). Labour Economics, $5(1), 25-51$.

Blackaby, D.H. \& Manning, D.N. (1990). The North-South Divide: Questions of Existence and Stability. The Economic Journal, 100 (401), 510-527.

Blackaby, D.H. \& Manning, D.N. (1995). Earnings, unemployment and Britain's north-south divide: Real or imaginary? Oxford Bulletin of Economics and Statistics, 57, 487-512.

Blinder, A. S. (1973). Wage discrimination: reduced forms and structural estimates. Journal of Human Resources, 8, $436-55$.

Briant, A., Combes, P.P. \& Lafourcade, M. (2010). Dots to boxes: Do the size and shape of spatial units jeopardize economic geography estimations? Journal of Urban Economics, 67(3), 287-302. 
Bover, O. \& Velilla, P. (2005). Migrations in Spain: Historical Background and Current Trends”. In K. Zimmerman (Ed.), European Migration. What Do We Know? Oxford University Press.

Butcher, K.F. \& Di Nardo, J. (2002). The immigrant and native-born wage distributions: evidence from United States censuses, Industrial and Labor Relations Review, 56 (1), 97-121.

Card, D. \& de la Rica, S. (2006). Firm-level contracting and the structure of wages in Spain. Industrial and Labor Relations Review,59 (4), 573-592.

Combes, P.P., Duranton, G. \& Gobillon, L. (2008). Spatial wage disparities: Sorting matters! Journal of Urban Economies, 63, 723-742

Coondoo, D., Majumder, A. \& Ray, R. (2004). A method of calculating regional consumer price differentials with illustrative evidence from India. Review of Income and Wealth, 50, 51-68.

Costa, A., García, H., López, X.. \& Raymond, J.L. (2015). Estimació de les paritats de poder adquisitiu per a les comunitats autònomes espanyoles, Generalitat de Catalunya, Departament d'Economia i Coneixement, Monografía 17/2015.

Costa, A., García, J., Raymond, J.L. \& Sánchez-Serra, D. (2019, in press). Sub-national PPP in OECD countries: Estimates based on the Balassa-Samuelson hypothesis, OECD: Regional Development Working Papers.

Cuadrado-Roura, J. R. \& Maroto, A. (2016). Unbalanced regional resilience to the economic crisis in Spain: a tale of specialisation and productivity. Cambridge Journal of Regions, Economy and Society, 9 (1), $153-178$.

Decressin, J., Espinoza, R. A., Halikias, I., Kumhof, M., Leigh, D., Loungani, P., Medas, P. A., Mursula, S., Spilimbergo, A. \& Xu, T. (2015). Wage Moderation in Crises: Policy Considerations and Applications to the Euro Area. Staff Discussion Notes No. 15/22.

Di Nardo, J., Fortin, N.M., \& Lemieux, T. (1996). Labor market institutions and the distribution of wages, 1973-1992: A semi-parametric approach. Econometrica, 64 (5), 1011-1044.

Du Caju, P., Gautier, E., Momferatou, D. \& Ward-Warmedinger, M. (2008). Institutional features of wage bargaining in 23 European countries, the US and Japan, ECB Working Paper No 974. 
Duranton, G. \& Monastiriotis, V. (2002). Mind the gaps: the evolution of regional inequalities in the UK, 1982-1997. Journal of Regional Science, 42(2), 219-256.

Duranton, G. \& Puga, D. (2004). Micro-foundations of urban agglomeration economies. In Henderson, J. \& Thisse, J.-F. (Eds.), Handbook of Regional and Urban Economies (pp. 2063-2117). Amsterdam: Elsevier.

Elder, T.E., Goddeeris, J.H., \& Haider, S. J. (2010). Unexplained gaps and Oaxaca-Blinder decompositions. Labour Economics, 17(1), 284-290.

Engler, P. \& Klein, M. (2017). Austerity measures amplified crisis in Spain, Portugal and Italy. DIW Economic Bulletin, DIW Berlin, German Institute for Economic Research, 7(8), 89-93.

European Commission (2016). Country Report Spain 2016.

Eurostat (2015). People in the EU - who are we and how do we live?.

Eurostat (2016). Eurostat regional yearbook 2016 edition.

Firpo, S., Fortin, N. \& Lemieux, T. (2009). Unconditional Quantile Regressions. Econometrica, 77(3), $953-973$.

Fortin, N., Lemieux, T. \& Firpo, S. (2011). Decomposition Methods in Economics. In D. Card and O. Ashenfelter (Eds.) Handbook of Labor Economics, Volume 4 (pp. 1-102). Elsevier.

Galego, A.\& Pereira, J. (2014). Decomposition of regional wage differences along the wage distribution in Portugal: the importance of covariates. Environment and Planning A, 46(10), 2514-2532.

Groot, S. \& de Groot, H. (2011). Wage inequality in the Netherlands: Evidence, trends and explanations, CPB Discussion Paper No. 186.

Groot, S., Möhlmann, J., Garretsen, J. \& de Groot, H. (2011). The crisis sensitivity of European countries and regions: stylized facts and spatial heterogeneity. Ed. Cambridge.

Groot, S., de Groot, H. \& Smit, M. (2014). Regional wage differences in the Netherlands: Micro evidence on agglomeration externalities. Journal of Regional Science, 54 (3), 503-523. 
Håkansson, J.\& Isacsson, G. (2018, forthcoming). The spatial extent of agglomeration economies across the wage earnings distribution, Journal of Regional Science, 59, 281-301.

Hoffmaister, A. W. (2010), Barriers to retail competition and prices:evidence from Spain. Oxford Economic Papers, 62, 395-416.

International Monetary Fund (2015): Spain 2015 Article IV Consultation. Selected issues.

Janský, P. \& Kolcunová, D. (2017). Regional differences in price levels across the European Union and their implications for its regional policy. Annals in Regional Science, 58, 641-660.

Juhn, C., Murphy, K. \& Pierce, B. (1993). Wage inequality and the rise in returns to skill. Journal of Political Economy, $101,410-442$.

Kluge, J. \& Weber, M. (2018). Decomposing the German East-West wage gap. Economics of Transition, 26, 91125.

Liu, L. Q. (2018): Regional labour mobility in Spain (WP/18/282), IMF.

López-Bazo, E. \& Motellón, E. (2012). Human capital and regional wage gaps. Journal of Regional Studies. 46 (10), 1347-1365.

Lorente, J.R. (1992). La dispersión geográfica de los salarios. Síntesis Mensual de Indicadores Económicos, Ministerio de Economía y Hacienda.

Machado, J. A. \& Mata, J. (2005). Counterfactual decomposition of changes in wage distribution using quantile regression. Journal of Applied Econometrics, 20, 445-465.

Matano, A.\& Natichionni, P. (2012). Wage distribution and the spatial sorting of workers. Journal of Economic Geography, 12(2), 379-408.

Matano, A.\& Natichionni, P. (2016). What drives the urban wage premium? Evidence along the wage distribution. Journal of Regional Science, 56(2), 191-209.

Melly, B. (2005). Decomposition of differences in distribution using quantile regression. Labour Economics, 12, $577-590$.

This article is protected by copyright. All rights reserved. 
Melly, B. (2006). Estimation of counterfactual distributions using quantiles regression. Unpublished manuscript, University of St. Gallen.

Motellón, E. López-Bazo, E. and Attar, M. (2011). Regional heterogeneity in wage distributions: evidence from Spain. Journal of Regional Science, 51(3), 558-584.

Neumark, D. (1988). Employer's discriminatory behaviour and the estimation of wage discrimination. Journal of Human Resources, 23, 279-295.

Oaxaca, R. (1973). Male-female wage differentials in urban labour markets. International Economic Review, 14, 693-709.

Oaxaca, R., \& Ramson, M. (1994). On discrimination and the decomposition of wage differentials. Journal of Econometrics, 61, 5-22.

OECD (2014a). OECD Regional Outlook 2014.

OECD (2014b). The 2012 Labour Market Reform in Spain: A Preliminary Assessment, Ed. OECD Publishing.

Pereira, J. \& Galego, A. (2014). Inter-regional wage differentials in Portugal: an analysis across the wage distribution. Regional Studies, 48(9), 1529-1546.

Pereira, J. \& Galego, A. (2011). Regional wage differentials in Portugal: static and dynamic approaches. Papers in Regional Science, 90(3), 529-548.

Rosnick, D. \& Weisbrot, M. (2015). Has austerity worked in Spain?, CEPR Reports and Issue Briefs, 2015-27, Center for Economic and Policy Research (CEPR).

Samuelson, P.A. (1964): “Theoretical notes on trade problems”, Review of Economics and Statistics, 46, $145-154$.

Simón, H., Ramos, R. \& Sanromá, E. (2006). Collective bargaining and regional wage differences in Spain: an empirical analysis, Applied Economics, 38, 1749-1760.

Simón, H., Sanromá, E. \& Ramos, R. (2008). Labour segregation and immigrant and native-born wage distributions in Spain: an analysis using matched employer-employee data. Spanish Economic Review, 10 (2), 135-168. 
Simón, H., Sanromá, E., Ramos, R. (2017). Full- and part-time wage differences in Spain: An analysis along the wage distribution. International Journal of Manpower, 38(3), 449-469.

Simón, H.\& Russell, H. (2005). Firms and the gender pay gap: A cross-national comparison (Working Paper No.15). Pay Inequalities and Economic Performance.

Simón, H. (2010). International Differences in Wage Inequality: A New Glance with European Matched Employer-Employee Data. British Journal of Industrial Relations, 48(2), 310-346.

Simón, H. (2012). The gender gap in earnings: and international comparison with European matched employer-employee data. Applied Economics, 44, 1985-1999.

Vamvakidis, A. (2008). Regional Wage Differentiation and Wage Bargaining Systems in the European Union (Working Paper No. 08/43). IMF.

Vieira, J.A., Couto, J.P. \& Tiago, M.T. (2006). Inter-Regional Wage Dispersion in Portugal, Regional and Sectoral Economics Studies, 6 (1), 85-106.

\section{TABLES AND FIGURES}

TABLE 1. Regional purchasing power parities in Spain

\begin{tabular}{|c|c|c|c|c|}
\hline & 2012 & 2006 & 2010 & 2014 \\
\hline Spain & 100.00 & 100.00 & 100.00 & 100.00 \\
\hline Andalusia & 92.70 & 93.18 & 92.94 & 92.46 \\
\hline Aragon & 96.40 & 96.16 & 96.50 & 96.16 \\
\hline Asturias & 87.90 & 87.75 & 87.75 & 87.71 \\
\hline Balearic Islands & 98.90 & 99.50 & 99.17 & 99.39 \\
\hline Canary Islands & 83.10 & 85.33 & 83.92 & 82.29 \\
\hline
\end{tabular}




\begin{tabular}{|c|c|c|c|c|}
\hline Cantabria & 99.10 & 98.51 & 98.75 & 99.70 \\
\hline Castilla-La Mancha & 84.80 & 84.44 & 84.30 & 84.87 \\
\hline Castilla y León & 88.00 & 88.23 & 87.65 & 87.66 \\
\hline Catalonia & 108.50 & 107.04 & 107.98 & 109.15 \\
\hline Comunitat Valenciana & 93.00 & 93.23 & 93.09 & 92.78 \\
\hline Extremadura & 80.30 & 80.61 & 80.35 & 79.89 \\
\hline Galicia & 92.40 & 92.70 & 92.30 & 92.62 \\
\hline Madrid & 114.50 & 114.60 & 114.69 & 114.34 \\
\hline Murcia & 94.80 & 95.21 & 94.99 & 94.86 \\
\hline Navarra & 110.60 & 111.60 & 110.48 & 110.05 \\
\hline Basque Country & 107.70 & 107.37 & 107.94 & 108.21 \\
\hline Rioja & 90.40 & 90.30 & 90.08 & 90.27 \\
\hline Coefficient of variation & 0.102 & 0.104 & 0.105 & 0.107 \\
\hline Gini Index & .057 & .056 & .057 & .058 \\
\hline Minimum & 80.6 & 80.3 & 80.3 & 79.9 \\
\hline Maximum & 114.6 & 114.7 & 114.5 & 114.3 \\
\hline Maximum-Minimum (\% difference) & 42.18 & 42.69 & 42.74 & 43.11 \\
\hline
\end{tabular}

Notes: Original regional purchasing power parities correspond to 2012 and are drawn from Costa et al. (2015). In order to calculate the values corresponding to 2006, 2010 and 2014, the change in the value of the consumer price index between each year and 
2012 (measured from the average of all the months of the year) of each region has been applied (normalized with respect to the national average).

TABLE 2. Raw average hourly wages in Spanish regions

\begin{tabular}{|c|c|c|c|c|c|c|}
\hline & \multicolumn{3}{|c|}{$\begin{array}{c}\text { Not deflated with } \\
\text { purchasing power parities }\end{array}$} & \multicolumn{3}{|c|}{$\begin{array}{l}\text { Deflated with } \\
\text { purchasing power parities }\end{array}$} \\
\hline & 2006 & 2010 & 2014 & 2006 & 2010 & 2014 \\
\hline Spain & 9.36 & 10.62 & 10.95 & 9.36 & 10.62 & 10.95 \\
\hline Andalusia & 8.66 & 9.85 & 10.26 & 9.29 & 10.60 & 11.09 \\
\hline Aragon & 9.23 & 10.54 & 10.76 & 9.60 & 10.92 & 11.19 \\
\hline Asturias & 8.26 & 9.47 & 9.99 & 9.41 & 10.79 & 11.39 \\
\hline Balearic Islands & 8.74 & 10.12 & 9.99 & 8.78 & 10.20 & 10.06 \\
\hline Canary Islands & 7.78 & 9.08 & 9.29 & 9.12 & 10.82 & 11.28 \\
\hline Cantabria & 7.73 & 10.01 & 10.27 & 7.85 & 10.14 & 10.30 \\
\hline Castilla-La Mancha & 8.44 & 9.35 & 9.48 & 9.99 & 11.09 & 11.17 \\
\hline Castilla y León & 8.34 & 9.67 & 10.23 & 9.45 & 11.04 & 11.68 \\
\hline Catalonia & 10.14 & 11.49 & 11.70 & 9.48 & 10.65 & 10.72 \\
\hline Comunitat Valenciana & 8.61 & 10.06 & 10.28 & 9.23 & 10.81 & 11.08 \\
\hline Extremadura & 7.41 & 8.40 & 7.87 & 9.19 & 10.45 & 9.85 \\
\hline Galicia & 7.99 & 9.20 & 9.59 & 8.62 & 9.97 & 10.36 \\
\hline Madrid & 10.91 & 11.86 & 12.23 & 9.52 & 10.34 & 10.70 \\
\hline
\end{tabular}




\begin{tabular}{|c|c|c|c|c|c|c|}
\hline Murcia & 7.86 & 9.34 & 10.10 & 8.26 & 9.83 & 10.64 \\
\hline Navarra & 10.19 & 11.10 & 11.85 & 9.13 & 10.05 & 10.77 \\
\hline Basque Country & 11.08 & 12.72 & 13.52 & 10.32 & 11.79 & 12.50 \\
\hline Rioja & 8.02 & 9.30 & 9.83 & 8.88 & 10.32 & 10.89 \\
\hline Coefficient of variation & 0.129 & 0.112 & 0.125 & 0.065 & 0.047 & 0.058 \\
\hline Gini Index & .067 & .058 & .063 & .034 & .025 & .031 \\
\hline Minimum & 7.41 & 8.40 & 7.87 & 7.85 & 9.83 & 9.85 \\
\hline Maximum & 11.08 & 12.72 & 13.52 & 10.32 & 11.79 & 12.50 \\
\hline Maximum-Minimum (percent difference) & 49.50 & 51.50 & 71.85 & 31.42 & 19.92 & 26.87 \\
\hline
\end{tabular}

Notes: Hourly wages are measured in euros.

TABLE 3. Raw hourly wages in Spanish regions along the wage distribution

\begin{tabular}{|c|c|c|c|c|c|c|c|c|c|}
\hline & & 2006 & & & 2010 & & & 2014 & \\
\hline & P10 & P50 & P90 & P10 & P50 & P90 & P10 & P50 & P90 \\
\hline Spain & 4.87 & 7.53 & 15.95 & 5.60 & 8.64 & 17.78 & 5.86 & 9.02 & 18.27 \\
\hline Andalusia & 5.16 & 7.68 & 15.32 & 5.95 & 8.66 & 17.71 & 6.23 & 8.99 & 18.18 \\
\hline Aragon & 5.20 & 8.06 & 15.56 & 6.09 & 9.08 & 17.49 & 6.55 & 9.28 & 18.02 \\
\hline Asturias & 5.34 & 7.97 & 15.36 & 6.34 & 9.03 & 16.90 & 6.65 & 9.71 & 18.10 \\
\hline Balearic Islands & 5.05 & 7.19 & 14.30 & 5.80 & 8.27 & 16.41 & 6.22 & 8.60 & 15.51 \\
\hline
\end{tabular}




\begin{tabular}{|c|c|c|c|c|c|c|c|c|c|}
\hline Canary Islands & 4.95 & 7.39 & 15.34 & 6.09 & 8.57 & 18.49 & 6.31 & 9.27 & 18.63 \\
\hline Cantabria & 4.76 & 6.86 & 12.58 & 5.57 & 8.44 & 16.76 & 5.83 & 8.73 & 17.13 \\
\hline Castilla-La Mancha & 5.69 & 7.64 & 17.66 & 6.54 & 8.97 & 17.91 & 6.75 & 9.29 & 18.05 \\
\hline Castilla y León & 5.31 & 7.62 & 15.84 & 6.19 & 8.84 & 18.52 & 6.83 & 9.47 & 18.85 \\
\hline Catalonia & 4.70 & 7.68 & 16.34 & 5.42 & 8.64 & 17.81 & 5.65 & 8.95 & 17.92 \\
\hline Comunitat Valenciana & 5.23 & 7.55 & 15.12 & 5.95 & 8.71 & 18.14 & 6.30 & 9.11 & 18.16 \\
\hline Extremadura & 5.46 & 7.18 & 16.41 & 6.43 & 8.46 & 17.06 & 6.42 & 8.72 & 13.65 \\
\hline Galicia & 4.77 & 6.87 & 15.18 & 5.69 & 7.99 & 15.87 & 6.10 & 8.59 & 16.99 \\
\hline Madrid & 4.38 & 7.29 & 16.87 & 4.97 & 8.25 & 18.09 & 5.21 & 8.52 & 18.77 \\
\hline Murcia & 4.90 & 7.13 & 12.68 & 5.51 & 7.88 & 16.11 & 5.66 & 8.31 & 19.26 \\
\hline Navarra & 5.24 & 7.52 & 14.48 & 5.98 & 8.75 & 15.15 & 6.17 & 9.46 & 16.30 \\
\hline Basque Country & 5.25 & 8.76 & 17.18 & 6.18 & 10.13 & 18.78 & 6.46 & 10.87 & 20.20 \\
\hline Rioja & 5.62 & 7.73 & 14.09 & 6.53 & 8.90 & 15.06 & 6.61 & 9.43 & 16.51 \\
\hline Coefficient of variation & 0.067 & 0.062 & 0.092 & 0.071 & 0.059 & 0.067 & 0.070 & 0.066 & 0.088 \\
\hline Gini Index & .036 & .032 & .050 & .039 & .030 & .037 & .037 & .033 & .045 \\
\hline Minimum & 4.38 & 6.86 & 12.58 & 4.97 & 7.88 & 15.06 & 5.21 & 8.31 & 13.65 \\
\hline Maximum & 5.69 & 8.76 & 17.66 & 6.54 & 10.13 & 18.78 & 6.83 & 10.87 & 20.20 \\
\hline Maximum-Minimum (\% difference) & 29,91 & 27,70 & 40,38 & 31,59 & 28,55 & 24,70 & 31,09 & 30,81 & 47,99 \\
\hline
\end{tabular}

Notes: Hourly wages are measured in euros controlling for regional purchasing power parities. 
TABLE 4. Correlation between raw regional wages along percentiles of the wage distribution

\begin{tabular}{lccc}
\hline & 2006 & 2010 & 2014 \\
\hline P10-P50 & $.441^{*}$ & $.554^{* *}$ & $.597^{* *}$ \\
P50-P90 & $.508^{* *}$ & .391 & .362 \\
& & & \\
P10-P90 & .175 & -.043 & -.117 \\
\hline
\end{tabular}

$* * *, * *$ and $*$ indicate significance at the $1 \%, 5 \%$ and $10 \%$ levels.

TABLE 5. Standard deviation of unexplained components of regional wages along percentiles of the wage distribution

\begin{tabular}{llll}
\hline & 2006 & 2010 & 2014 \\
\hline P10 & .064 & .072 & .075 \\
P50 & .057 & .054 & .060 \\
& & & \\
P90 & .083 & .064 & .075 \\
\hline
\end{tabular}

TABLE 6. Correlation between unexplained components of regional wages

\begin{tabular}{cccc}
\multicolumn{4}{c}{ along percentiles of the wage distribution } \\
\hline & 2006 & 2010 & 2014 \\
\hline P10-P50 & $.769 * * *$ & $.904^{* * *}$ & $.869^{* * *}$ \\
P50-P90 & $.489^{* *}$ & $.581^{* *}$ & $.540^{* *}$ \\
P10-P90 & $.654^{* * *}$ & $.679^{* * *}$ & $.476^{* *}$ \\
\hline
\end{tabular}

$* * *, * *$ and $*$ indicate significance at the $1 \%, 5 \%$ and $10 \%$ levels.

This article is protected by copyright. All rights reserved. 
TABLE 7. Correlation between unexplained components of regional wages

\begin{tabular}{cccc}
\multicolumn{4}{c}{ across time } \\
\hline & P10 & P50 & P90 \\
\hline $2006-2010$ & $0.968^{* * *}$ & $0.888^{* * *}$ & $0.812^{* * *}$ \\
& & & \\
$2010-2014$ & $0.957^{* * *}$ & $0.958^{* * *}$ & $0.779^{* * *}$ \\
& & & \\
$2006-2014$ & $0.938^{* * *}$ & $0.805^{* * *}$ & $0.643^{* * *}$ \\
\hline
\end{tabular}

***, ${ }^{* *}$ and $*$ indicate significance at the $1 \%, 5 \%$ and $10 \%$ levels.

FIGURE 1.

Regional purchasing power parities (Spain=100)

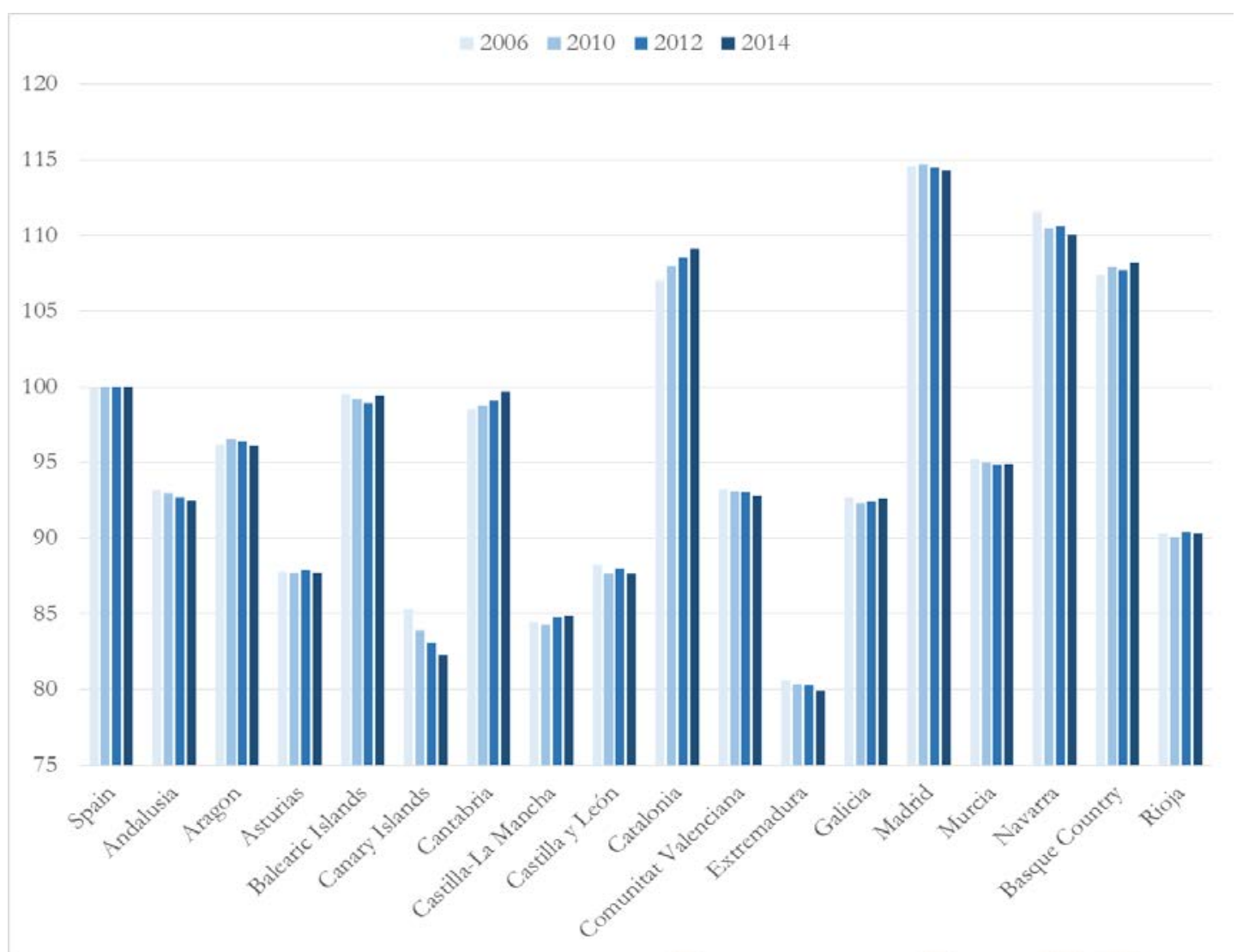

This article is protected by copyright. All rights reserved. 
FIGURE 2.

Average hourly wages of Spanish regions. Raw wages (upper panel) and raw wages deflated by regional purchasing power parities (lower panel)

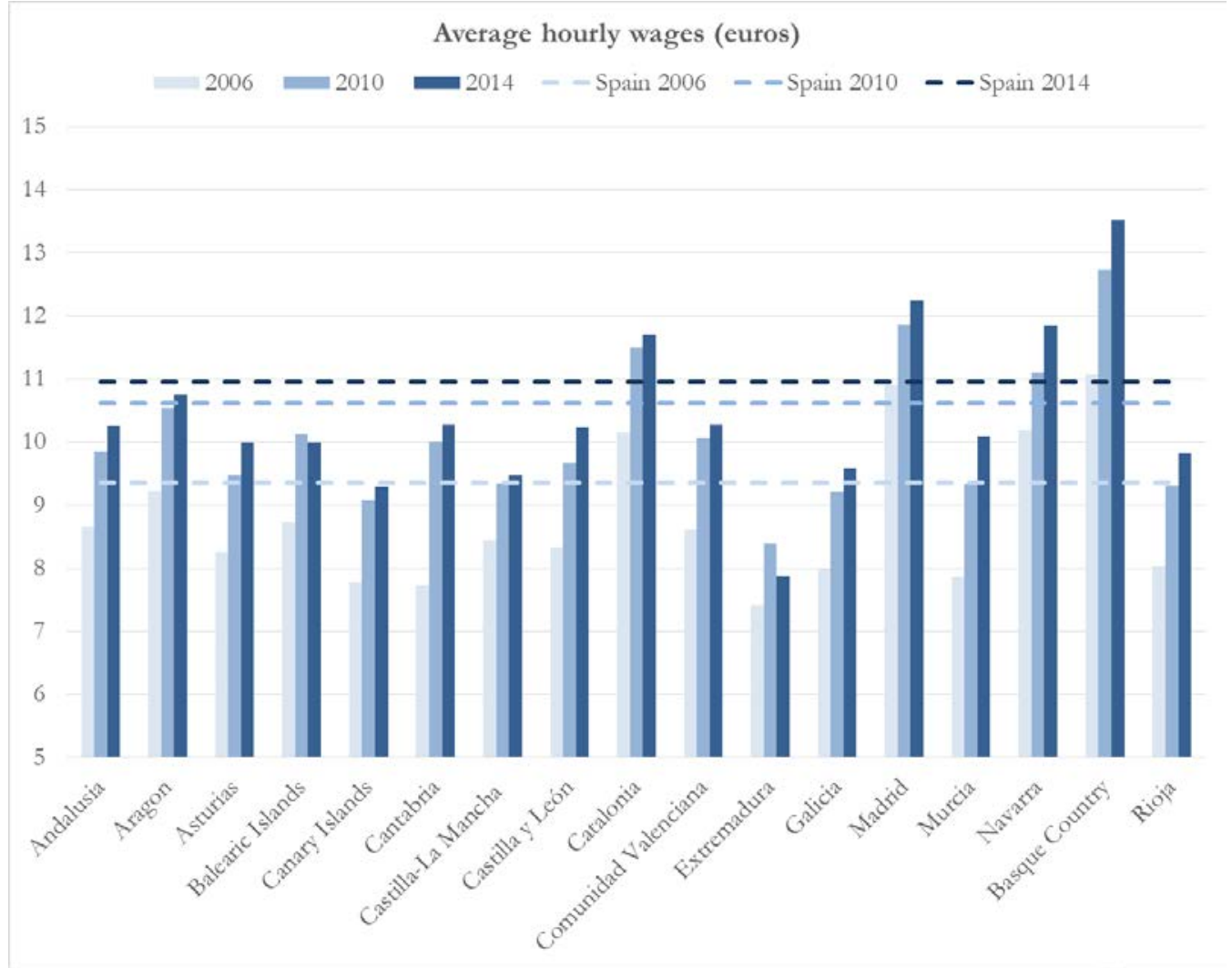

Average hourly wages with PPPs (euros)

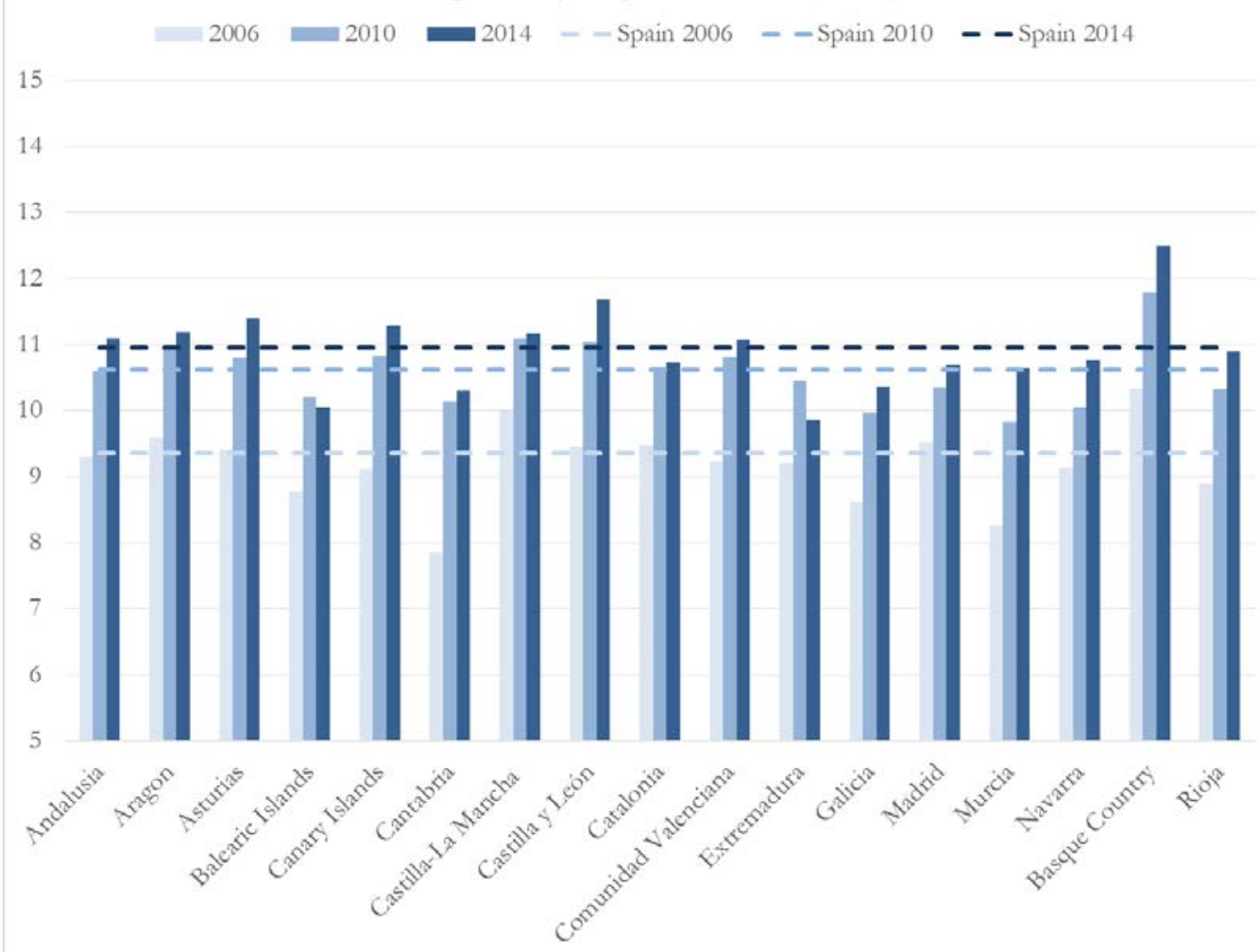

This article is protected by copyright. All rights reserved. 
FIGURE 3.

Regional raw average hourly wages of Spanish regions with and without regional purchasing power parities.

2006 (upper panel), 2010 (intermediate panel) and 2014 (lower panel)
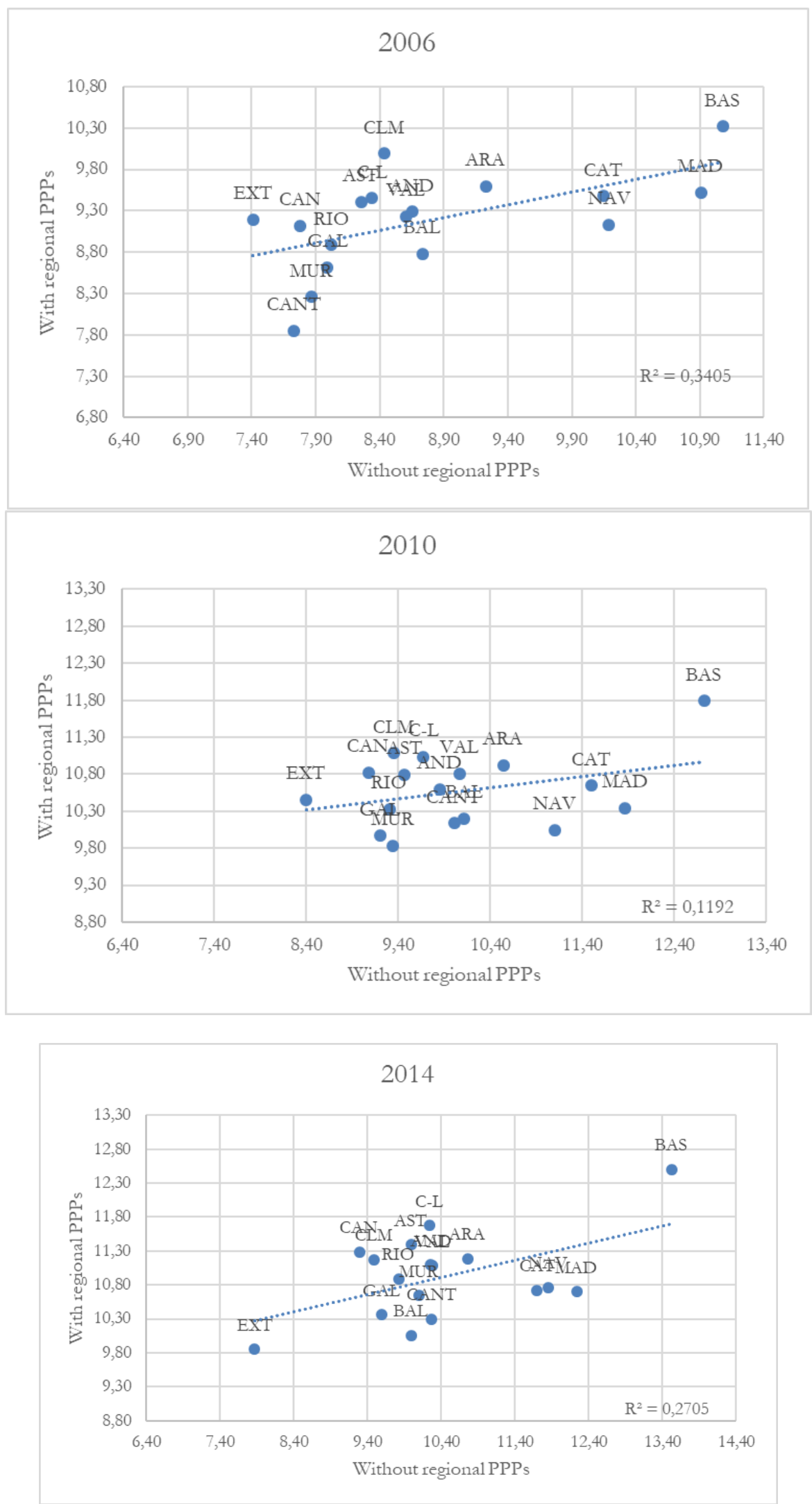

This article is protected by copyright. All rights reserved. 


\section{FIGURE 4.}

Inter-regional raw wage differences along the wage distribution. 2006 (upper panel), 2010 (intermediate panel) and 2014 (lower panel)
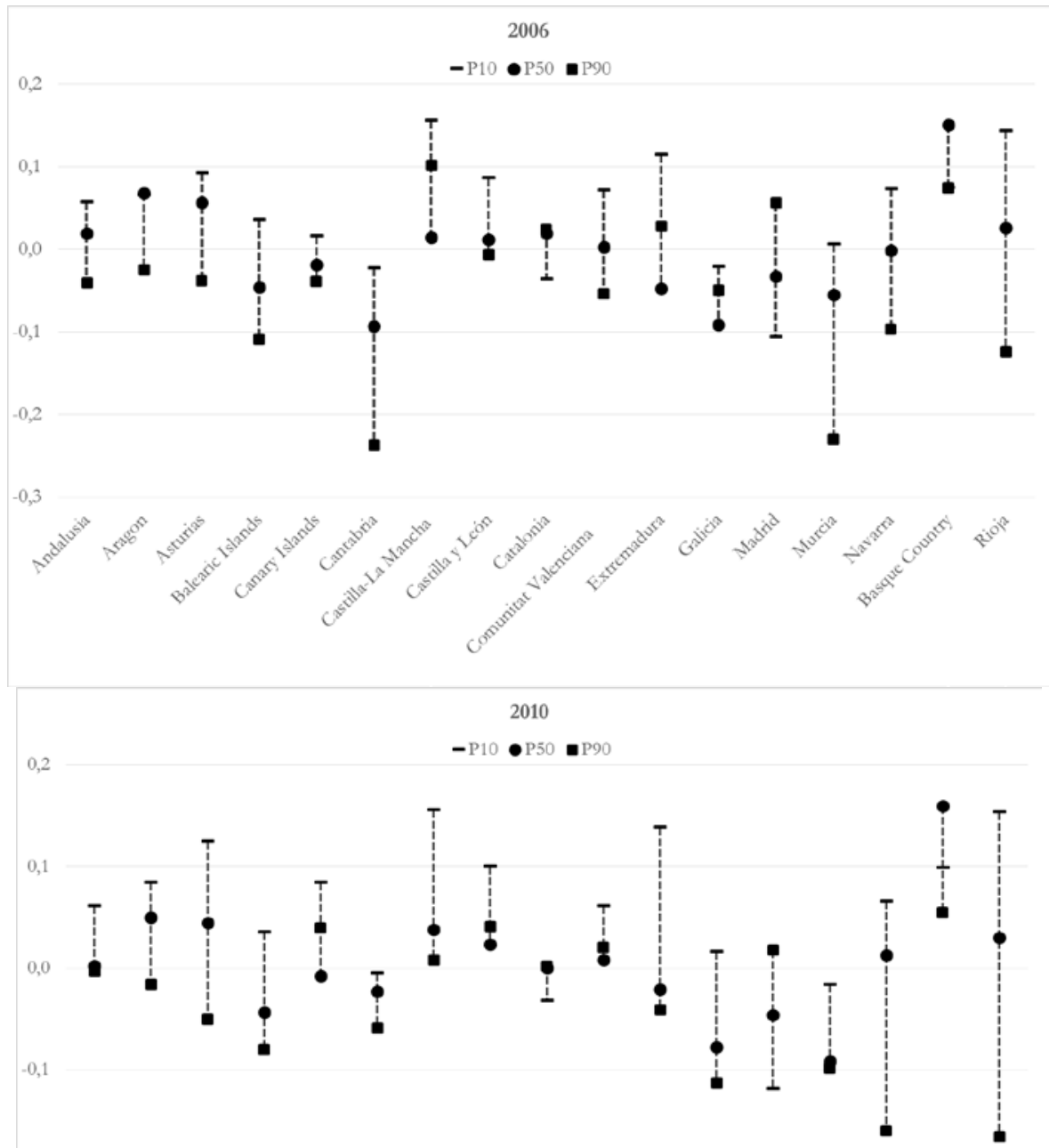

$-0,2$

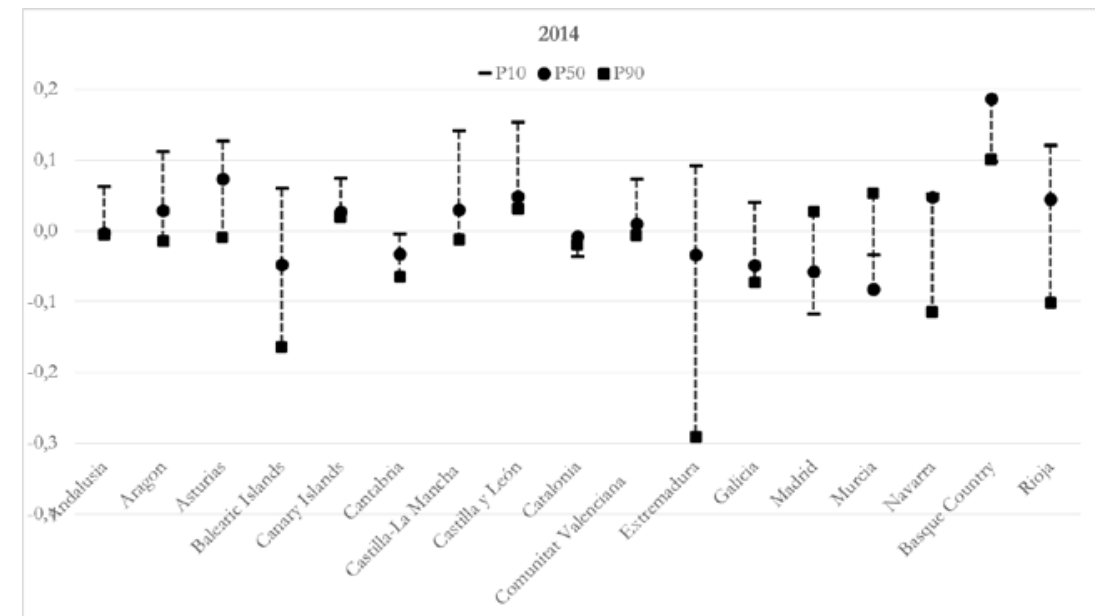

This article is protected by copyright. All rights reserved. 


\section{FIGURE 5.}

Decomposition of inter-regional differences in raw average wages. 2006 (upper panel), 2010 (intermediate panel) and 2014 (lower panel).

Oaxaca-Blinder methodology
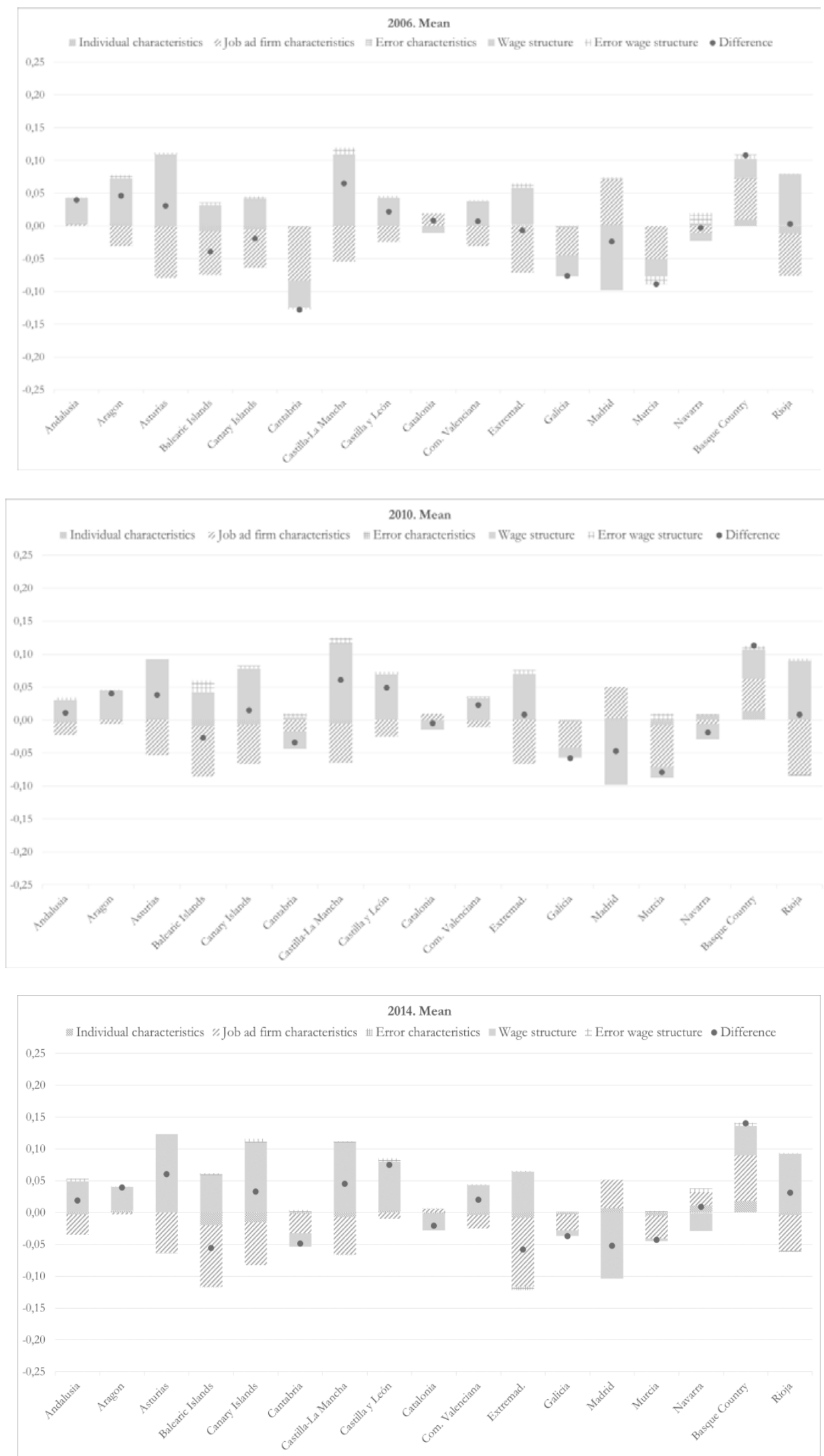

This article is protected by copyright. All rights reserved. 
FIGURE 6.

Decomposition of inter-regional raw wage differences. First decile.

2006 (upper panel), 2010 (intermediate panel) and 2014 (lower panel).

\section{Fortin-Lemieux-Firpo methodology}
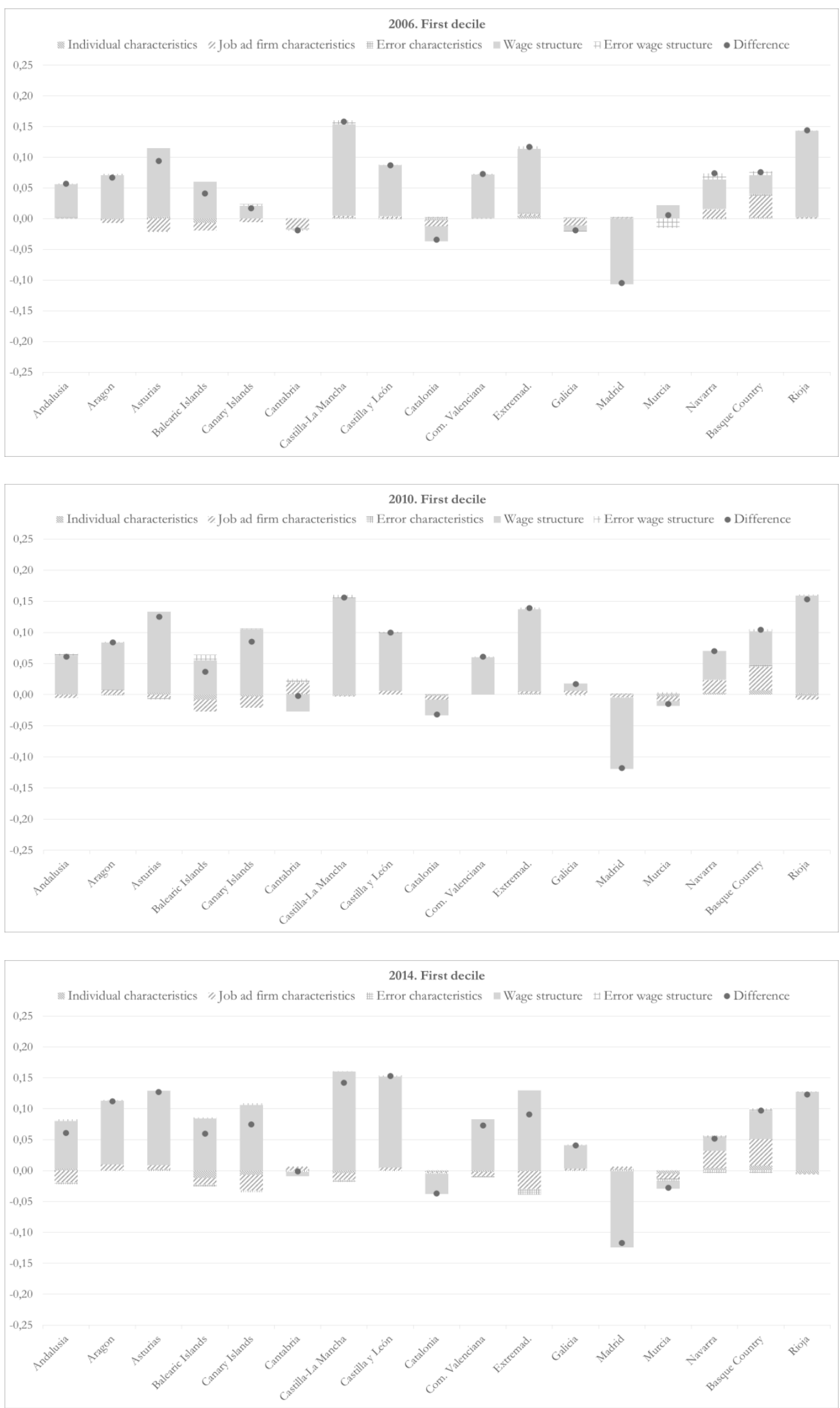

This article is protected by copyright. All rights reserved. 


\section{FIGURE 7.}

Decomposition of inter-regional raw wage differences. Median. 2006 (upper panel), 2010 (intermediate panel) and 2014 (lower panel).

\section{Fortin-Lemieux-Firpo methodology}
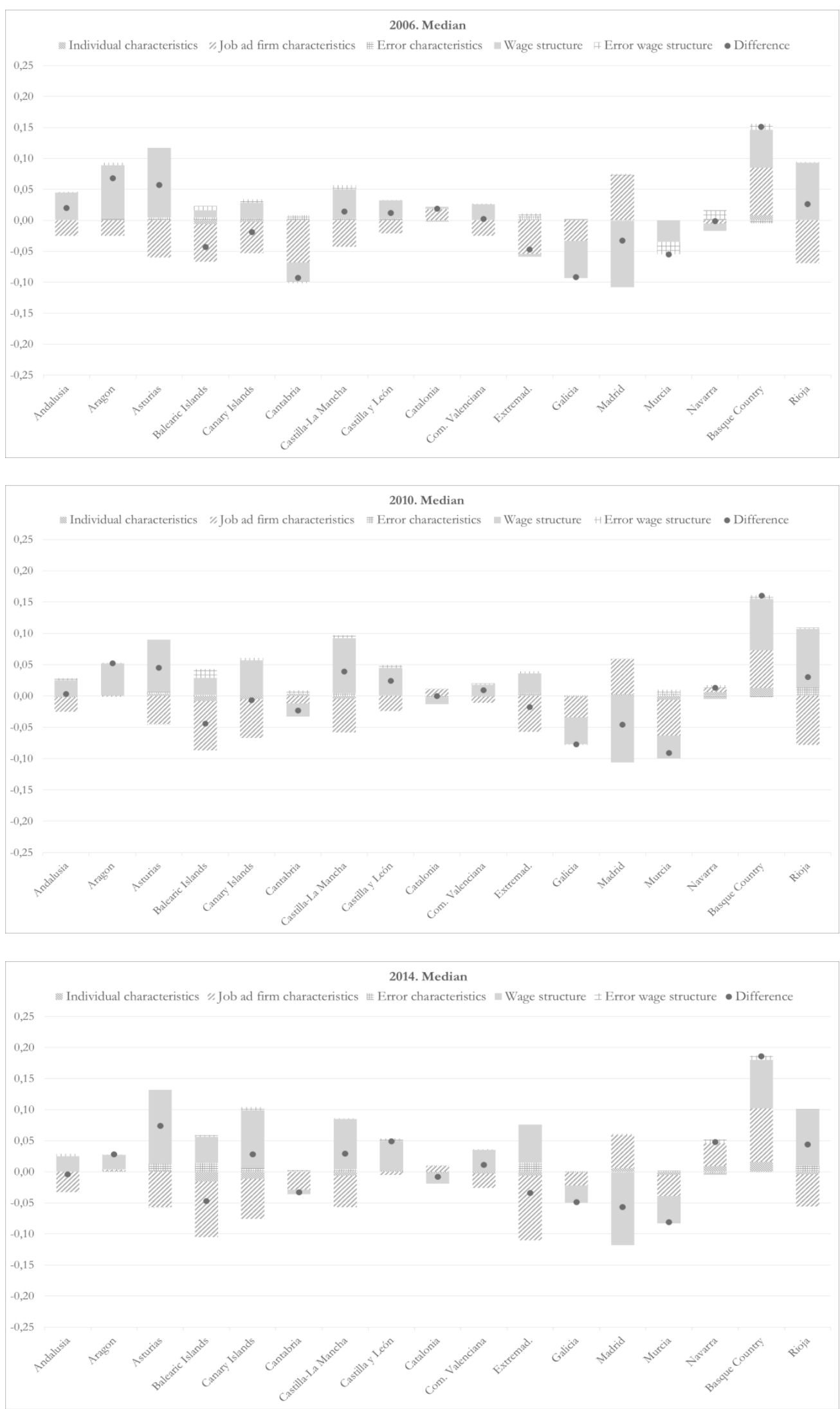

This article is protected by copyright. All rights reserved. 


\section{FIGURE 8.}

Decomposition of inter-regional raw wage differences. Ninth decile. 2006 (upper panel), 2010 (intermediate panel) and 2014 (lower panel).

\section{Fortin-Lemieux-Firpo methodology}
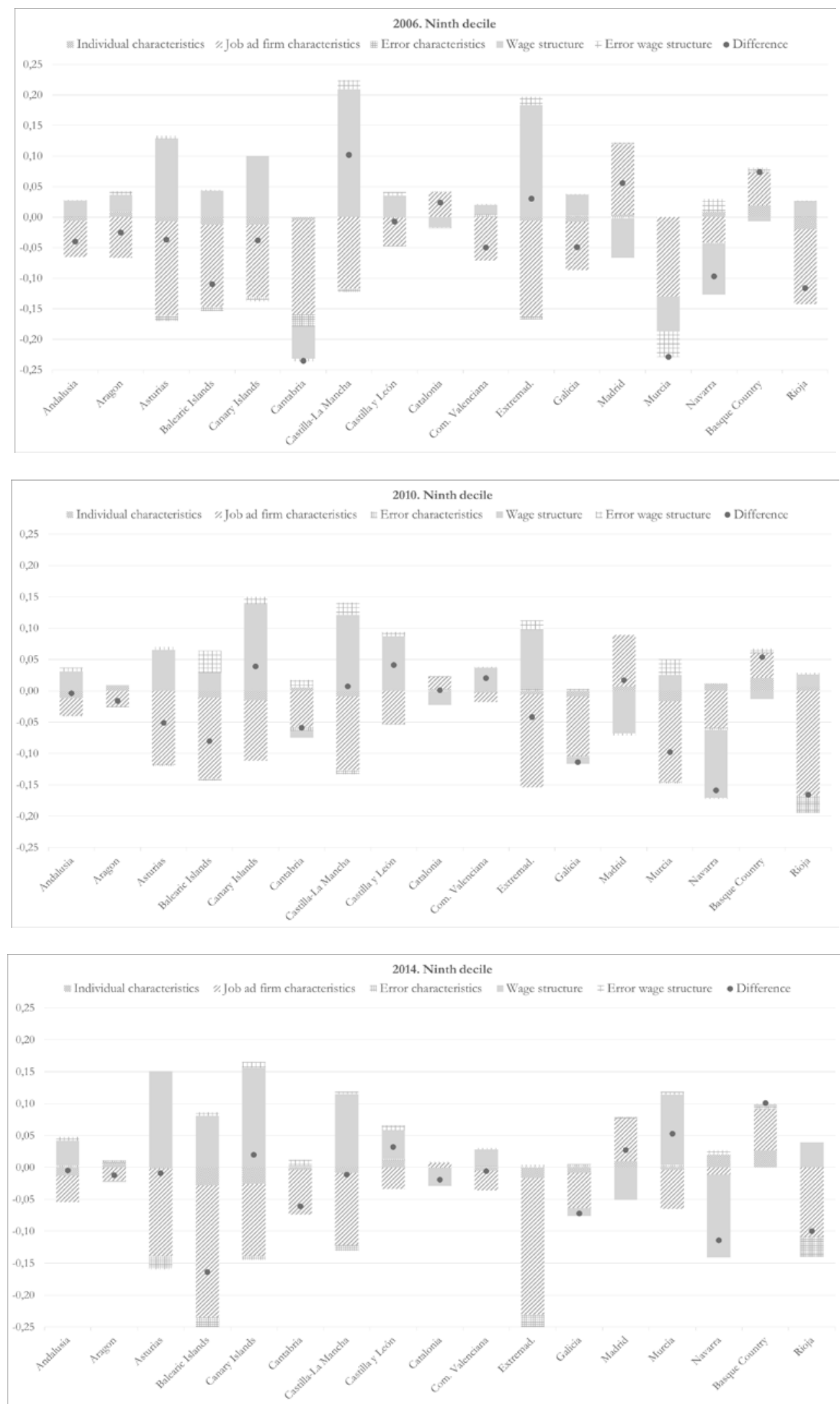

This article is protected by copyright. All rights reserved. 


\section{FIGURE 9.}

Unexplained components of inter-regional wage differences along the wage distribution. 2006 (upper panel), 2010 (intermediate panel) and 2014 (lower panel)
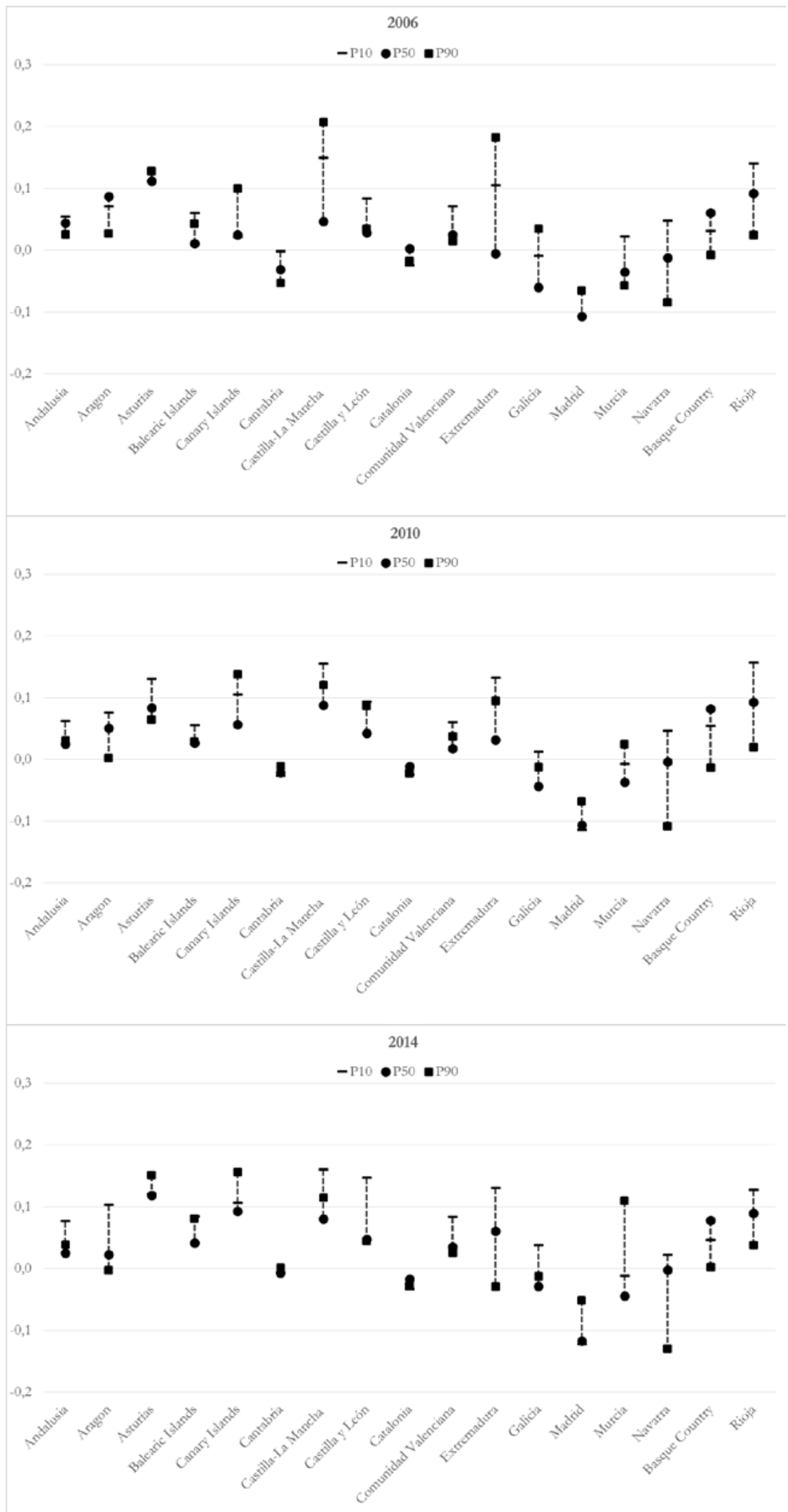

Notes: The unexplained component of regional wages corresponds to the pure wage structure effect of the decomposition of interregional wage as expressed in equation (5).

This article is protected by copyright. All rights reserved. 


\section{APPENDIX}

TABLE A.1. Descriptive evidence (average) of explanatory variables. 2006

SpainAndalusiaAragonAsturias
Bal. Canary
Isl. Isl. ${ }^{\text {Cantabria }}{ }_{\text {Man.León }}$ CataloniaCom.Val.Extremad.GaliciaMadridMurciaNavarra ${ }_{\text {Casque }}{ }_{\text {Rioja }}$

\begin{tabular}{|c|c|c|c|c|c|c|c|c|c|c|c|c|c|c|c|c|c|}
\hline Male & .585 & .631 & .601 & .584 & .560 & .590 & .605 & .637 .591 & .550 & .631 & .635 & .571 & .546 & .636 & .572 & .582 & .625 \\
\hline Immigrant & .093 & .054 & .127 & .041 & .165 & .092 & .061 & . 1065 & .112 & .112 & .024 & .035 & .115 & .142 & .118 & .034 & .135 \\
\hline Age $<30$ & .260 & .295 & .240 & .258 & .265 & .256 & .264 & .299 .254 & .249 & .287 & .287 & .253 & .243 & .273 & .242 & .205 & .258 \\
\hline Age $>45$ & .258 & .205 & .294 & .252 & .270 & .239 & .267 & .240 .282 & .285 & .258 & .234 & .269 & .255 & .224 & .262 & .310 & .259 \\
\hline Age $30-45$ & .482 & .500 & .466 & .489 & .465 & .506 & .469 & .461. 464 & .466 & .456 & .479 & .478 & .503 & .503 & .497 & .485 & .483 \\
\hline $\begin{array}{l}\text { Education: } \\
\text { primary }\end{array}$ & .276 & .301 & .295 & .196 & .370 & .352 & .288 & .289 .315 & .241 & .347 & .271 & .289 & .221 & .337 & .283 & .211 & .517 \\
\hline $\begin{array}{l}\text { Education: } \\
\text { secondary }\end{array}$ & .439 & .448 & .454 & .567 & .448 & .443 & .501 & . 501.403 & .459 & .420 & .512 & .436 & .417 & .472 & .366 & .380 & .242 \\
\hline Education: tertiary & .285 & .250 & .251 & .237 & .182 & .205 & .211 & .210. 282 & .299 & .233 & .217 & .275 & .362 & .190 & .351 & .409 & .241 \\
\hline Tenure & 6.016 & 4.422 & 6.491 & 5.064 & 5.782 & 4.881 & 5.071 & 5.2096 .326 & 6.884 & 5.926 & 5.168 & 5.862 & 6.387 & 4.618 & 6.555 & 8.350 & 5.907 \\
\hline $\begin{array}{l}\text { Fixed-term } \\
\text { contract }\end{array}$ & .308 & .431 & .301 & .398 & .311 & .343 & .326 & .386 .345 & .218 & .318 & .381 & .326 & .259 & .374 & .278 & .283 & .264 \\
\hline Part-time & .168 & .188 & .178 & .171 & .134 & .126 & .165 & .125 .172 & .185 & .155 & .147 & .141 & .164 & .170 & .165 & .170 & .162 \\
\hline Supervisory tasks & .180 & .180 & .161 & .169 & .202 & .167 & .164 & .160 .167 & 184 & .181 & 136 & .154 & 199 & .162 & 172 & .181 & .188 \\
\hline $\begin{array}{l}\text { Directors and } \\
\text { managers }\end{array}$ & .021 & .014 & .019 & .012 & .013 & .018 & .017 & 012.019 & .022 & .017 & .004 & .016 & .035 & .008 & .018 & .020 & .015 \\
\hline $\begin{array}{l}\text { Techn. and scient. } \\
\text { prof. }\end{array}$ & .107 & .097 & .078 & .076 & .069 & .066 & .062 & .095.098 & 112 & .083 & .099 & .090 & .146 & .076 & .139 & .150 & .063 \\
\hline $\begin{array}{l}\text { Technicians and } \\
\text { assoc. prof. }\end{array}$ & .135 & .103 & .123 & .102 & .092 & .090 & .114 & .078 .101 & .176 & .117 & .068 & .092 & .191 & .088 & .083 & 118 & .086 \\
\hline $\begin{array}{l}\text { Office and admin. } \\
\text { staff }\end{array}$ & .135 & .145 & .107 & .104 & .156 & .142 & .093 & .122 & .136 & .137 & 116 & .132 & .153 & .120 & .086 & 112 & .093 \\
\hline
\end{tabular}




\begin{tabular}{|c|c|c|c|c|c|c|c|c|c|c|c|c|c|c|c|c|c|c|}
\hline $\begin{array}{l}\text { Caterers and } \\
\text { vendors }\end{array}$ & .152 & .157 & .164 & .207 & .186 & .189 & .203 & .125 & .150 & .150 & .134 & .166 & .176 & .143 & .138 & .133 & .148 & .150 \\
\hline $\begin{array}{l}\text { Workers skilled in } \\
\text { agriculture }\end{array}$ & .003 & .003 & .002 & .001 & .005 & .008 & .004 & .001 & .002 & .001 & .002 & .001 & .001 & .004 & .003 & .000 & .003 & .002 \\
\hline $\begin{array}{l}\text { Skilled in manuf. } \\
\text { and constr. }\end{array}$ & .180 & .193 & .224 & .213 & .186 & .161 & .240 & .250 & .214 & .154 & .220 & .191 & .207 & .130 & .240 & .209 & .184 & .252 \\
\hline $\begin{array}{l}\text { Oper. of plant and } \\
\text { machinery }\end{array}$ & .102 & .102 & .100 & .092 & .063 & .084 & .083 & .133 & .110 & .109 & .129 & .133 & .122 & .058 & .126 & .157 & .138 & .153 \\
\hline $\begin{array}{l}\text { Elementary } \\
\text { occupations }\end{array}$ & .165 & .185 & .183 & .193 & .231 & .242 & .184 & .200 & .185 & .141 & .161 & .222 & .164 & .140 & .200 & .173 & .127 & .186 \\
\hline $\begin{array}{l}\text { Mining } \\
\text { quarrying }\end{array}$ & .002 & .002 & .001 & .000 & .000 & .000 & .000 & .003 & .006 & .001 & .001 & .007 & .008 & .000 & .003 & .000 & .002 & .000 \\
\hline Manufacturing & .139 & .095 & .220 & .107 & .039 & .035 & .098 & .175 & .134 & .193 & .195 & .094 & .142 & .074 & .138 & .208 & .243 & .270 \\
\hline $\begin{array}{l}\text { Prod. of electr. gas } \\
\text { and water }\end{array}$ & .002 & .003 & .000 & .000 & .000 & .003 & .000 & .000 & .000 & .001 & .002 & .000 & .000 & .004 & .000 & .000 & .000 & .000 \\
\hline Construction & .187 & .233 & .190 & .253 & .240 & .225 & .287 & .280 & .234 & .128 & .218 & .267 & .204 & .138 & .274 & .231 & .135 & .261 \\
\hline Trade & .188 & .187 & .152 & .203 & .197 & .222 & .205 & .142 & .141 & .204 & .212 & .195 & .184 & .182 & .200 & .142 & .156 & .159 \\
\hline Hospitality & .072 & .090 & .066 & .094 & .231 & .176 & .095 & .053 & .073 & .056 & .057 & .074 & .073 & .057 & .051 & .074 & .050 & .074 \\
\hline $\begin{array}{l}\text { Transport } \\
\text { commun. }\end{array}$ & .050 & .044 & .064 & .041 & .039 & .039 & .054 & .039 & .041 & .045 & .044 & .045 & .049 & .075 & .042 & .035 & .038 & .033 \\
\hline $\begin{array}{l}\text { Financial } \\
\text { intermediation }\end{array}$ & .032 & .030 & .027 & .006 & .025 & .025 & .000 & .035 & .040 & .033 & .027 & .025 & .036 & .050 & .012 & .002 & .011 & .004 \\
\hline $\begin{array}{l}\text { Real estate and } \\
\text { rental }\end{array}$ & .169 & .146 & .143 & .175 & .086 & .139 & .160 & .114 & .157 & .167 & .121 & .134 & .145 & .263 & .151 & .140 & .155 & .119 \\
\hline Education & .045 & .051 & .024 & .030 & .036 & .017 & .035 & .044 & .042 & .056 & .039 & .024 & .024 & .048 & .021 & .032 & .079 & .042 \\
\hline Health & .084 & .090 & .091 & .055 & .065 & .090 & .043 & .102 & .113 & .085 & .061 & .126 & .099 & .072 & .086 & .116 & .104 & .013 \\
\hline $\begin{array}{l}\text { Other social and } \\
\text { services act. }\end{array}$ & .029 & .029 & .022 & .036 & .044 & .028 & .023 & .013 & .019 & .031 & .022 & .012 & .037 & .037 & .021 & .019 & .027 & .026 \\
\hline Size $<20$ & .383 & .431 & .431 & .485 & .499 & .384 & .515 & .461 & .443 & .355 & .438 & .551 & .466 & .243 & .480 & .405 & .358 & .517 \\
\hline Size $20-49$ & .204 & .197 & .225 & .247 & .235 & .216 & .272 & .242 & .235 & .207 & .212 & .217 & .219 & .149 & .248 & .297 & .225 & .400 \\
\hline
\end{tabular}




\begin{tabular}{|c|c|c|c|c|c|c|c|c|c|c|c|c|c|c|c|c|c|c|}
\hline Size 50-99 & .097 & .093 & .102 & .094 & .097 & .117 & .099 & .092 & .083 & .100 & .107 & .078 & .098 & .088 & .106 & .114 & .101 & .070 \\
\hline Size 100-199 & .064 & .066 & .053 & .035 & .051 & .091 & .047 & .045 & .069 & .062 & .061 & .028 & .049 & .076 & .050 & .076 & .080 & .012 \\
\hline Size $200-499$ & .086 & .060 & .075 & .099 & .051 & .071 & .068 & .079 & .079 & .101 & .060 & .068 & .073 & .122 & .038 & .026 & .122 & .000 \\
\hline Size $>499$ & .166 & .153 & .114 & .040 & .067 & .121 & .000 & .081 & .091 & .176 & .122 & .058 & .095 & .322 & .078 & .083 & .113 & .000 \\
\hline $\begin{array}{l}\text { Coll. agr.: sectoral } \\
\text { national }\end{array}$ & .370 & .292 & .354 & .361 & .310 & .286 & .350 & .370 & .347 & .405 & .394 & .240 & .308 & .495 & .423 & .226 & .125 & .383 \\
\hline $\begin{array}{l}\text { Coll. agr.: sectoral } \\
\text { subnational }\end{array}$ & .563 & .593 & .583 & .632 & .690 & .688 & .636 & .620 & .636 & .536 & .569 & .752 & .672 & .409 & .577 & .756 & .671 & .600 \\
\hline Coll. agr.: firm & .067 & .115 & .062 & .008 & .000 & .026 & .014 & .011 & .017 & .059 & .036 & .007 & .021 & .096 & .000 & .018 & .204 & .018 \\
\hline $\begin{array}{l}\text { Proportion } \\
\text { unskilled in firm }\end{array}$ & .165 & .185 & .183 & .193 & .231 & .242 & .184 & .200 & .185 & .141 & .161 & .222 & .164 & .140 & .200 & .173 & .127 & .186 \\
\hline $\begin{array}{l}\text { Proportion skilled } \\
\text { in firm }\end{array}$ & .263 & .214 & .220 & .190 & .173 & .174 & .194 & .186 & .217 & .310 & .217 & .172 & .198 & .372 & .173 & .240 & .289 & .164 \\
\hline $\begin{array}{l}\text { Proportion prim. } \\
\text { stud. in firm }\end{array}$ & .276 & .301 & .295 & .196 & .370 & .352 & .288 & .289 & .315 & .241 & .347 & .271 & .289 & .221 & .337 & .283 & .211 & .517 \\
\hline $\begin{array}{l}\text { Proportion tert. } \\
\text { stud. in firm }\end{array}$ & .285 & .250 & .251 & .237 & .182 & .205 & .211 & .210 & .282 & .299 & .233 & .217 & .275 & .362 & .190 & .351 & .409 & .241 \\
\hline $\begin{array}{l}\text { Proportion } \\
\text { females in firm }\end{array}$ & .414 & .368 & .399 & .416 & .440 & .410 & .395 & .363 & .409 & .450 & .369 & .365 & .429 & .454 & .364 & .428 & .418 & .375 \\
\hline $\begin{array}{l}\text { Proportion } \\
\text { immigr. in firm }\end{array}$ & .093 & .054 & .127 & .041 & .165 & .092 & .061 & .106 & .065 & .112 & .112 & .024 & .035 & .115 & .142 & .118 & .034 & .135 \\
\hline $\begin{array}{l}\text { Proportion fixed- } \\
\text { term in firm }\end{array}$ & .308 & .431 & .301 & .398 & .311 & .343 & .326 & .386 & .345 & .218 & .318 & .381 & .326 & .259 & .374 & .278 & .283 & .264 \\
\hline $\begin{array}{l}\text { Proportion part- } \\
\text { time in firm }\end{array}$ & .168 & .187 & .178 & .171 & .134 & .126 & .165 & .125 & .172 & .185 & .155 & .147 & .141 & .165 & .170 & .165 & .170 & .162 \\
\hline
\end{tabular}

\section{TABLE A.2. Descriptive evidence (average) of explanatory variables. 2010}

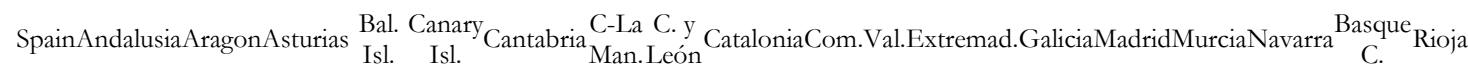

$\begin{array}{lllllllllllllllllllll}\text { Male } & .543 & .552 & .574 & .601 & .550 & .519 & .590 & .590 & .565 & .519 & .540 & & .609 & .545 & .520 & .544 & .615 & .590 & .603\end{array}$ 


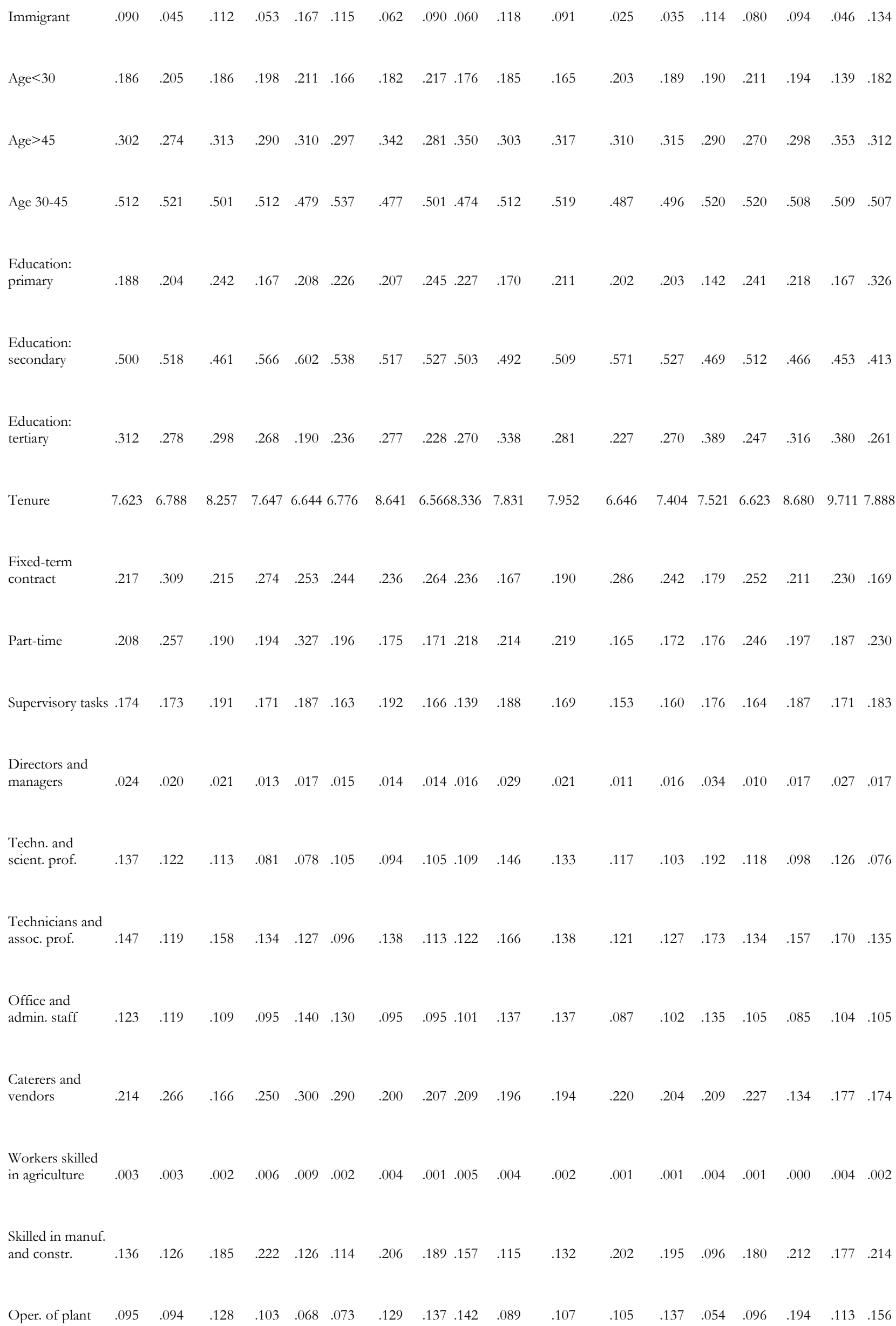


and machinery

Elementary

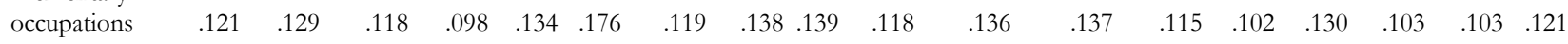

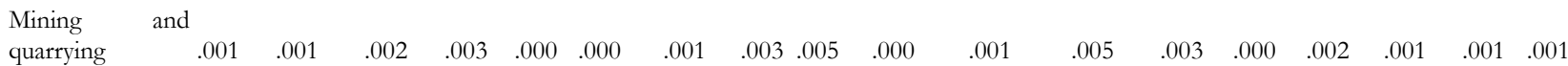

$\begin{array}{llllllllllllllllllll}\text { Manufacturing } & .178 & .127 & .294 & .266 & .064 & .062 & .271 & .237 & .236 & .193 & .205 & .155 & .232 & .094 & .199 & .445 & .303 & .387\end{array}$

Prod. of electr.

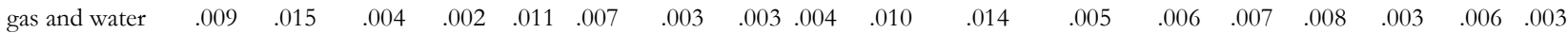

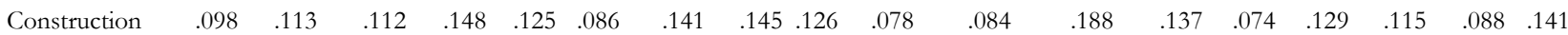

$\begin{array}{lllllllllllllllllll}\text { Trade } & .263 & .266 & .231 & .266 & .249 & .318 & .222 & .247 & .223 & .248 & .275 & .262 & .257 & .248 & .320 & .167 & .201 & .202\end{array}$

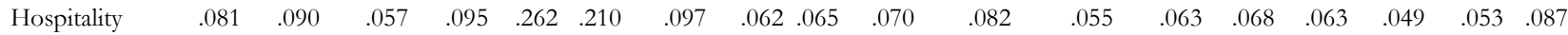

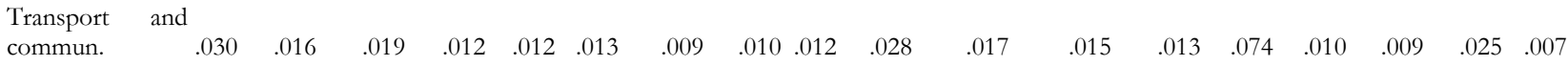

Financial

$\begin{array}{llllllllllllllllllllllll}\text { intermediation } & .030 & .030 & .022 & .009 & .016 & .016 & .007 & .030 & .024 & .032 & .030 & .013 & .017 & .050 & .007 & .007 & .021 & .014\end{array}$

Real estate and

$\begin{array}{lllllllllllllllllllllll}\text { rental } & .151 & .146 & .116 & .126 & .114 & .145 & .097 & .100 & .120 & .152 & .125 & .092 & .126 & .223 & .097 & .100 & .135 & .089\end{array}$

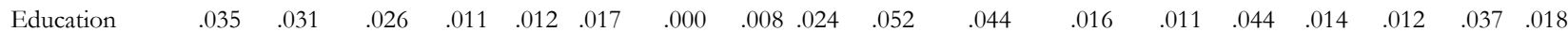

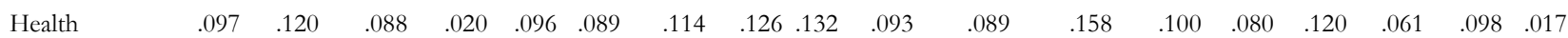

$\begin{array}{llllllllllllllllllllll}\begin{array}{l}\text { Other social and } \\ \text { services act. }\end{array} & .037 & .045 & .029 & .042 & .039 & .037 & .038 & .028 & .029 & .042 & .033 & & .035 & .037 & .036 & .031 & .030 & .031 & .033\end{array}$

$\begin{array}{llllllllllllllllllll}\text { Size }<20 & 418 & .470 & .481 & .532 & .568 & .469 & .536 & .558 & .498 & .361 & .445 & & .653 & .512 & .276 & .565 & .461 & .403 & .629\end{array}$

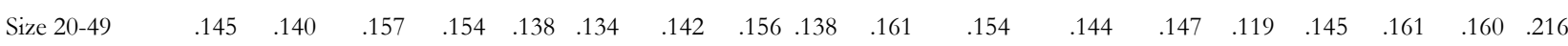

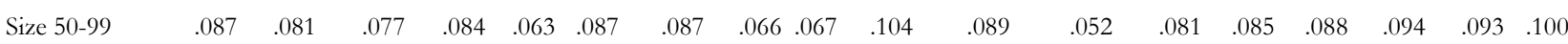

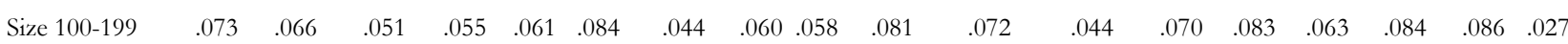

$\begin{array}{lllllllllllllllllllllll}\text { Size } 200-499 & .094 & .076 & .093 & .046 & .069 & .069 & .078 & .092 & .106 & .105 & .081 & .034 & .092 & .119 & .054 & .128 & .101 & .029\end{array}$

$\begin{array}{llllllllllllllllllllll}\text { Size }>499 & & .183 & .167 & .141 & .129 & .101 & .156 & .114 & .068 & .133 & .189 & .159 & & .073 & .098 & .317 & .085 & .073 & .157 & .000\end{array}$

This article is protected by copyright. All rights reserved. 
Coll. agr.:

$\begin{array}{llllllllllllllllllll}\text { sectoral national } & .271 & .243 & .303 & .179 & .204 & .213 & .211 & .233 & .245 & .280 & .263 & .309 & .230 & .360 & .287 & .227 & .145 & .325\end{array}$

Coll. agr.:

sectora

$\begin{array}{llllllllllllllllllllll}\text { subnational } & .522 & .512 & .469 & .653 & .631 & .571 & .502 & .598 & .544 & .566 & .551 & & .525 & .600 & .398 & .570 & .513 & .527 & .634\end{array}$

$\begin{array}{llllllllllllllllllll}\text { Coll. agr.: firm } & .207 & .245 & .228 & .168 & .165 & .216 & .287 & .169 & .211 & .154 & .185 & & .166 & .170 & .242 & .143 & .260 & .328 & .042\end{array}$

Proportion

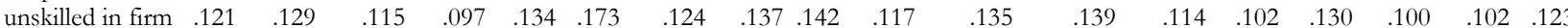

Proportion

$\begin{array}{llllllllllllllllllll}\text { skilled in firm } & .309 & .266 & .291 & .238 & .225 & .220 & .251 & .235 & .249 & .342 & .295 & .251 & .251 & .399 & .263 & .283 & .324 & .233\end{array}$

Proportion prim.

$\begin{array}{llllllllllllllllllll}\text { stud. in firm } & .189 & .206 & .238 & .165 & .209 & .222 & .203 & .244 & .224 & .171 & .208 & .208 & .205 & .143 & .245 & .205 & .168 & .324\end{array}$

Proportion tert.

$\begin{array}{lllllllllllllllllllll}\text { stud. in firm } & .312 & .282 & .294 & .275 & .193 & .237 & .279 & .229 & .270 & .335 & .284 & .228 & .272 & .388 & .247 & .314 & .374 & .268\end{array}$

Proportion

$\begin{array}{llllllllllllllllllll}\text { females in firm } & .452 & .447 & .422 & .417 & .447 & .477 & .406 & .407 & .430 & .472 & .457 & .390 & .451 & .471 & .452 & .389 & .411 & .404\end{array}$

Proportion

$\begin{array}{lllllllllllllllllllllll}\text { immigr. in firm } & .089 & .046 & .113 & .054 & .164 & .111 & .065 & .091 & .061 & .117 & .092 & .028 & .035 & .112 & .080 & .092 & .047 & .134\end{array}$

Proportion fixed-

$\begin{array}{llllllllllllllllllllll}\text { term in firm } & .217 & .313 & .216 & .272 & .253 & .240 & .234 & .264 & .239 & .166 & .197 & .288 & .240 & .178 & .243 & .207 & .224 & .177\end{array}$

Proportion part-

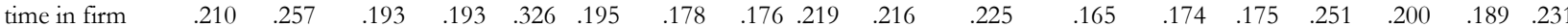

TABLE A.3. Descriptive evidence (average) of explanatory variables. 2014

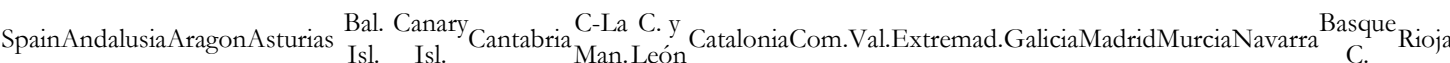

\begin{tabular}{|c|c|c|c|c|c|c|c|c|c|c|c|c|c|c|c|c|c|}
\hline Male & .529 & .548 & .561 & .589 & .506 & .513 & .523 & .578 & .556 & .507 & .531 & .605 & .518 & .508 & .561 & .608 & .548 \\
\hline Immigrant & .075 & .045 & .076 & .034 & .127 & .095 & .036 & .077 & .051 & .092 & .075 & .038 & .027 & .096 & .090 & .066 & .045 \\
\hline Age $<30$ & .133 & .124 & .139 & .126 & .167 & .142 & .138 & .155 & .124 & .143 & .119 & .166 & .131 & .137 & .154 & .121 & .092 \\
\hline Age $>45$ & .345 & .295 & .370 & .337 & .355 & .327 & .366 & .328 & .408 & .351 & .366 & .286 & .350 & .326 & .336 & .381 & .421 \\
\hline
\end{tabular}

This article is protected by copyright. All rights reserved. 


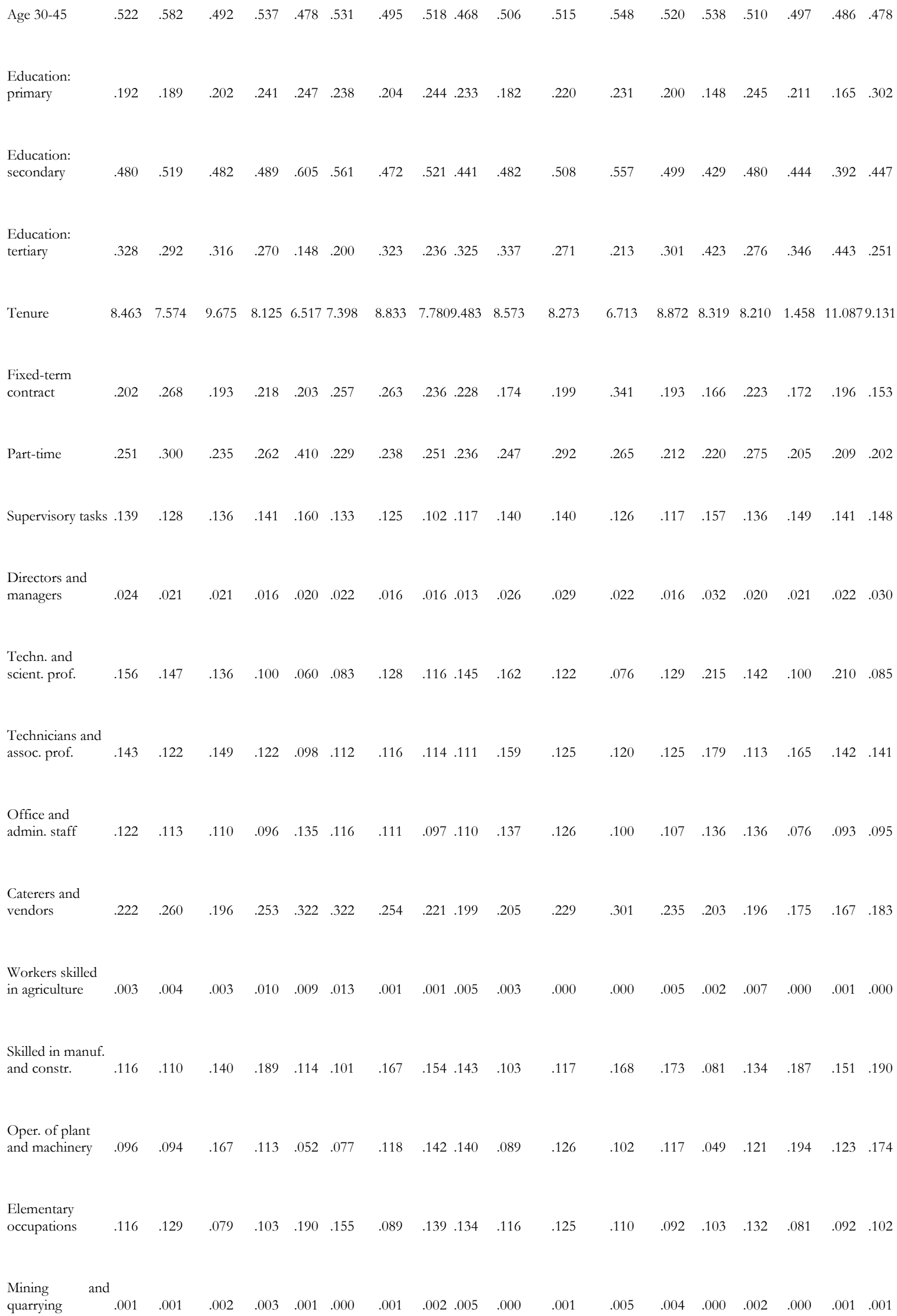




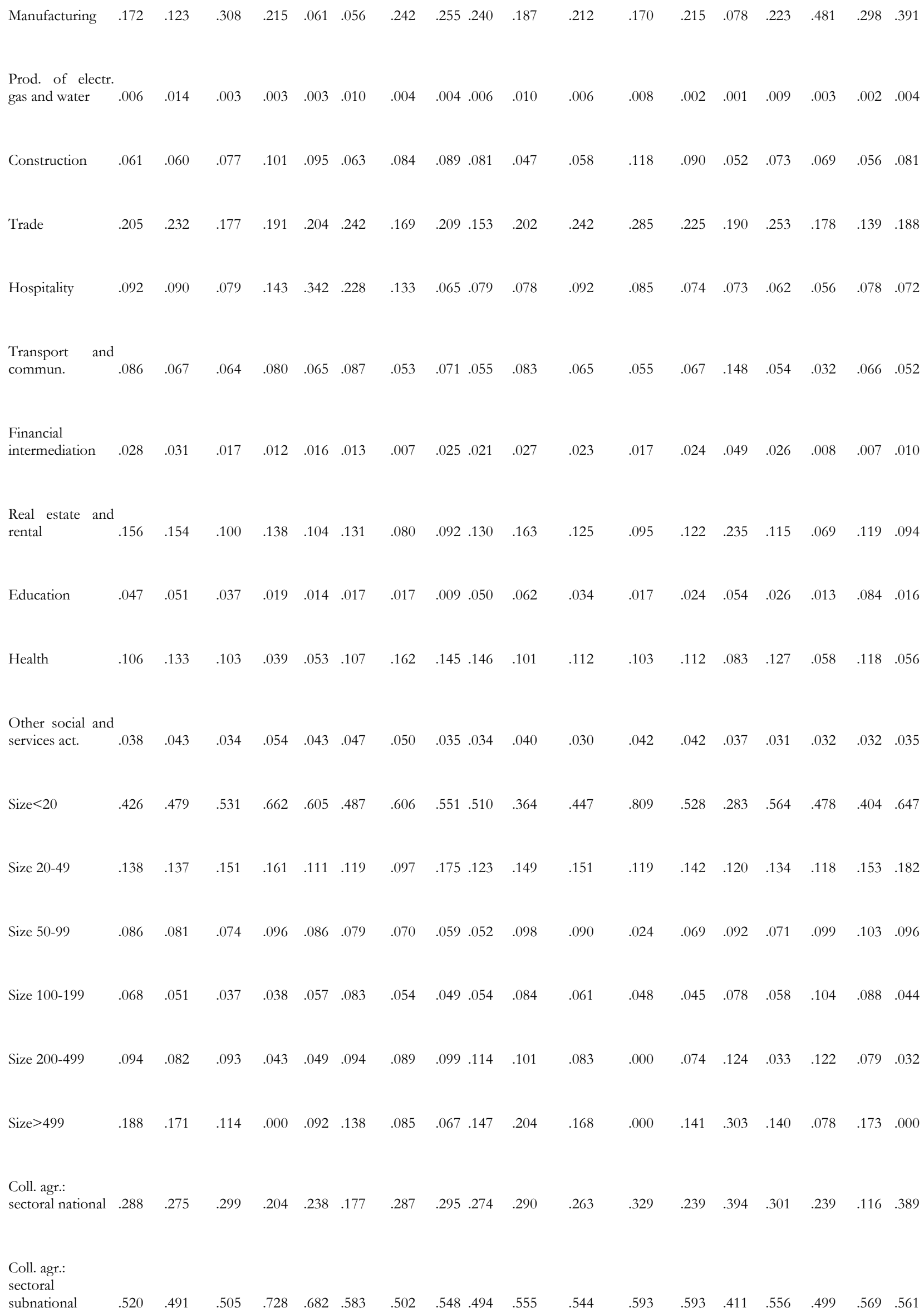




\begin{tabular}{|c|c|c|c|c|c|c|c|c|c|c|c|c|c|c|c|c|c|c|}
\hline Coll. agr.: firm & .193 & .235 & .196 & .068 & .080 & .240 & .211 & .157 & .231 & .155 & .193 & .079 & .169 & .195 & .143 & .262 & .314 & .051 \\
\hline $\begin{array}{l}\text { Proportion } \\
\text { unskilled in firm }\end{array}$ & .114 & .124 & .078 & .104 & .179 & .155 & .090 & .131 & .130 & .111 & .122 & .102 & .092 & .105 & .126 & .082 & .092 & .094 \\
\hline $\begin{array}{l}\text { Proportion } \\
\text { skilled in firm }\end{array}$ & .337 & .308 & .317 & .246 & .203 & .233 & .280 & .259 & .294 & .366 & .295 & .267 & .277 & .429 & .289 & .299 & .368 & .277 \\
\hline $\begin{array}{l}\text { Proportion prim. } \\
\text { stud. in firm }\end{array}$ & .187 & .186 & .198 & .240 & .241 & .229 & .199 & .241 & .223 & .178 & .202 & .216 & .204 & .145 & .245 & .200 & .173 & .283 \\
\hline $\begin{array}{l}\text { Proportion tert. } \\
\text { stud. in firm }\end{array}$ & .341 & .307 & .326 & .277 & .177 & .219 & .336 & .249 & .341 & .351 & .296 & .257 & .308 & .428 & .287 & .358 & .429 & .267 \\
\hline $\begin{array}{l}\text { Proportion } \\
\text { females in firm }\end{array}$ & .464 & .446 & .429 & .403 & .489 & .490 & .469 & .409 & .447 & .483 & .463 & .408 & .476 & .479 & .425 & .389 & .451 & .430 \\
\hline $\begin{array}{l}\text { Proportion } \\
\text { immigr. in firm }\end{array}$ & .073 & .045 & .075 & .040 & .117 & .095 & .035 & .075 & .053 & .086 & .074 & .036 & .030 & .092 & .093 & .063 & .049 & .093 \\
\hline $\begin{array}{l}\text { Proportion fixed- } \\
\text { term in firm }\end{array}$ & .201 & .252 & .186 & .218 & .202 & .259 & .259 & .231 & .237 & .177 & .203 & .305 & 194 & .164 & .224 & .172 & .201 & .162 \\
\hline $\begin{array}{l}\text { Proportion part- } \\
\text { time in firm }\end{array}$ & .237 & .280 & .217 & .251 & .385 & .227 & .229 & .230 & .224 & .229 & .273 & .231 & .207 & .212 & .256 & .197 & .202 & 193 \\
\hline
\end{tabular}

TABLE A.4. Decomposition of raw inter-regional wage differences in average wages in Spain. Oaxaca-Blinder methodology

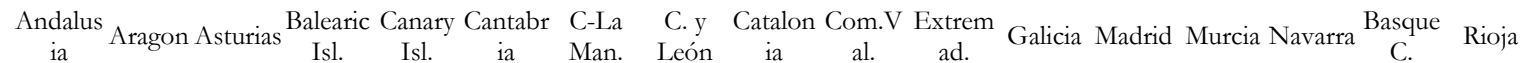

2006

Overall

$\begin{array}{llllllllllllllllll}\text { difference } & 0.040 & 0.046 & 0.031 & -0.039 & -0.019 & -0.128 & 0.065 & 0.022 & 0.008 & 0.007 & -0.007 & -0.076 & -0.024 & -0.089 & -0.003 & 0.108 & 0.003\end{array}$

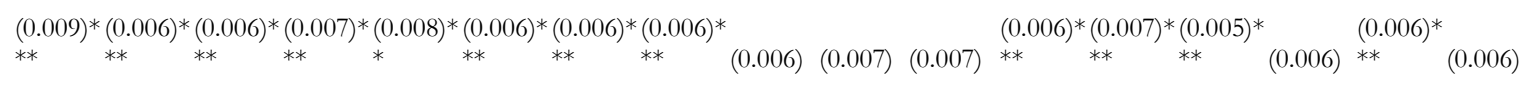

Compositi

on $\quad \begin{array}{lllllllllllllllll}0.000 & -0.029 & -0.080 & -0.075 & -0.064 & -0.083 & -0.053 & -0.024 & 0.017 & -0.031 & -0.070 & -0.044 & 0.071 & 0.000 & -0.008 & 0.072 & -0.077\end{array}$

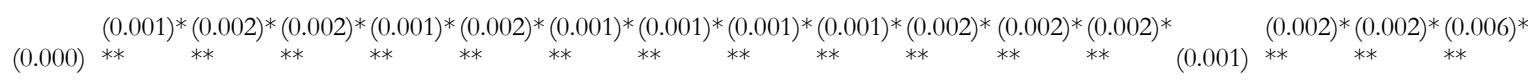

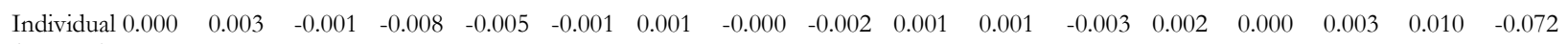
characteris

This article is protected by copyright. All rights reserved. 


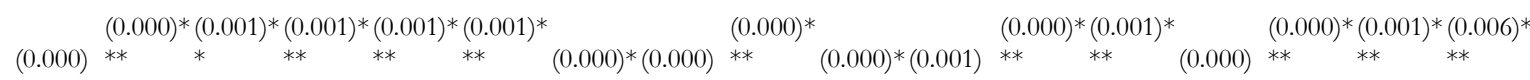

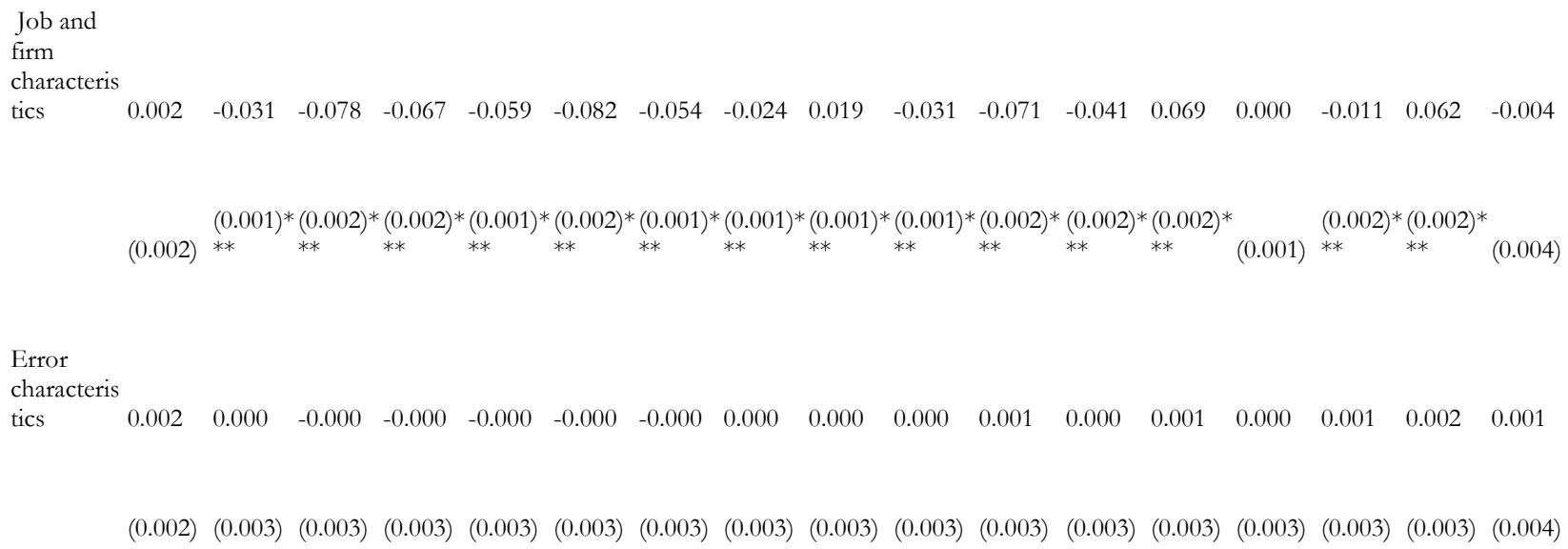




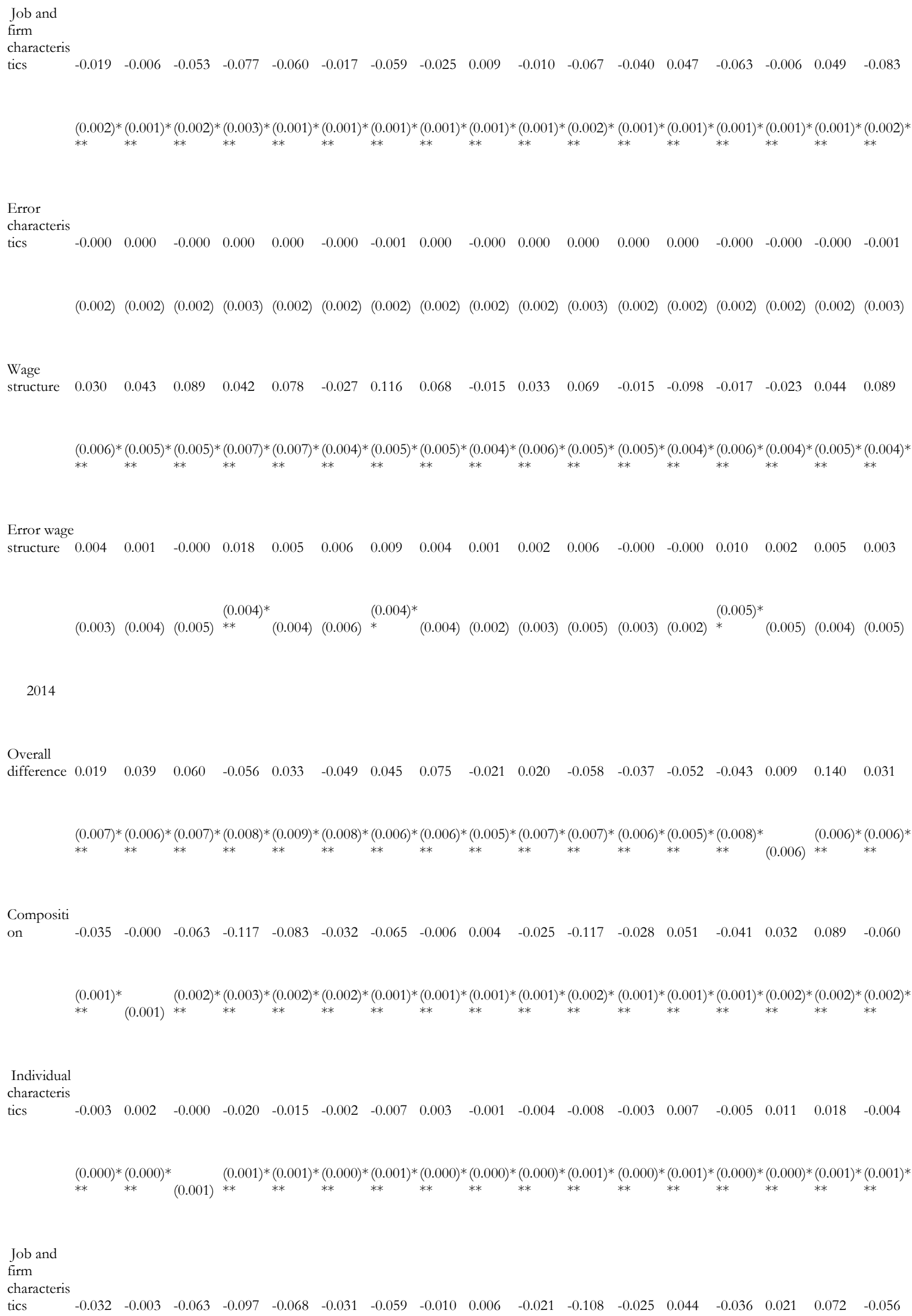




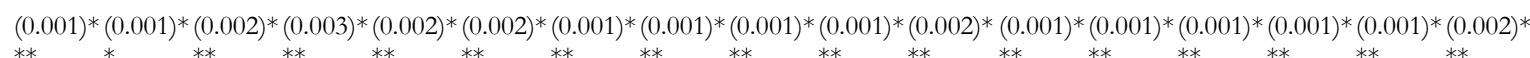

Error

characteris

$\begin{array}{llllllllllllllllll}\text { tics } & 0.000 & 0.001 & 0.000 & -0.001 & 0.000 & -0.000 & -0.001 & 0.000 & -0.000 & 0.000 & -0.006 & 0.001 & -0.000 & 0.000 & -0.001 & -0.000 & -0.002\end{array}$

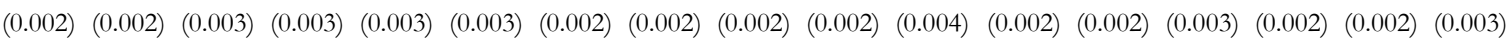

Wage

$\begin{array}{llllllllllllllllll}\text { structure } & 0.049 & 0.037 & 0.123 & 0.059 & 0.110 & -0.021 & 0.110 & 0.077 & -0.027 & 0.043 & 0.064 & -0.009 & -0.104 & -0.004 & -0.028 & 0.046 & 0.092\end{array}$

$(0.007) *(0.005) *(0.005) *(0.008) *(0.008) *(0.005) *(0.005) *(0.005) *(0.004) *(0.006) *(0.004) *$
$* *$

Error wage

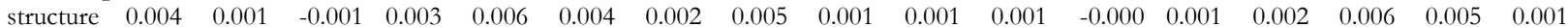

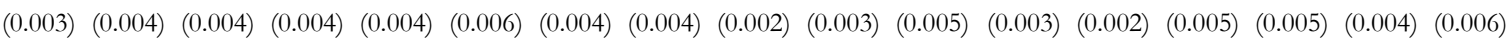

Notes: Hourly wages are measured in euros considering regional purchasing power parities. The estimates corresponds to a specification of the wage equation that includes as control variables both individual characteristics (gender, age, education and nationality) and attributes of the job and the firm (tenure, type of contract, full- or part-time, supervisory tasks, occupation, sector, size, type of collective agreement, type of control, type of market, the proportion of females and immigrants in the firm, the proportion of workers with fixed-term contracts and with part-time in the firm, the proportion of workers working in unskilled and skilled occupations in the firm and the proportion of workers with primary and tertiary studies in the firm). ${ }^{* *}$, ** and $*$ indicate significance at the $1 \%, 5 \%$ and $10 \%$ levels, respectively.

TABLE A.5. Decomposition of raw inter-regional wage differences along the wage distribution in Spain. 2006. Fortin-Lemieux-Firpo methodology

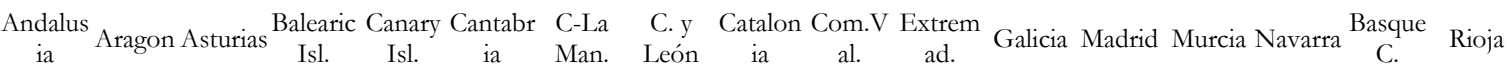

P 10

Overall

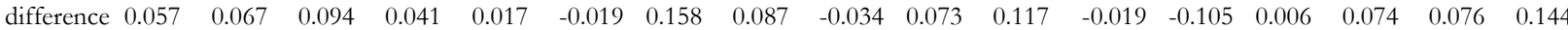

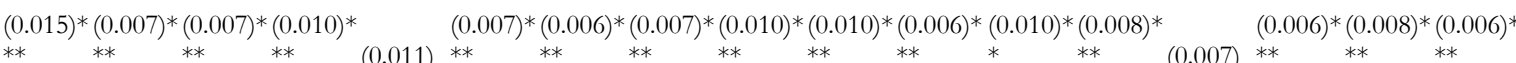

$\begin{aligned} & \text { Compositi } \\ & \text { on }\end{aligned}$
$\begin{array}{lllllllllllllllllll} & 0.001 & -0.007 & -0.019 & -0.019 & -0.006 & -0.015 & 0.003 & 0.003 & -0.012 & 0.001 & 0.006 & -0.011 & 0.000 & 0.000 & 0.014 & 0.037 & 0.001\end{array}$

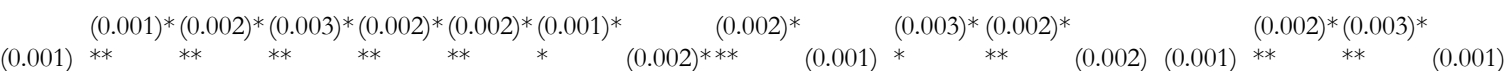

Individual

characteris

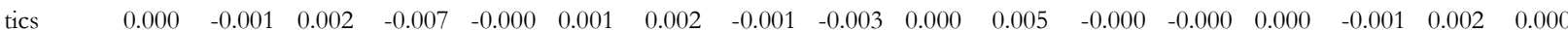




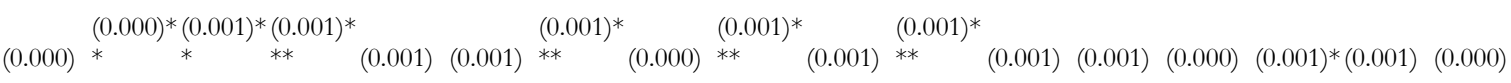

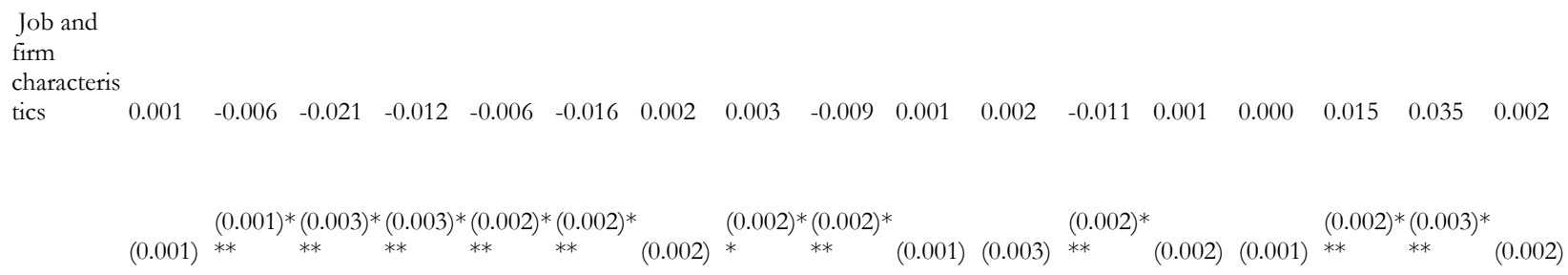




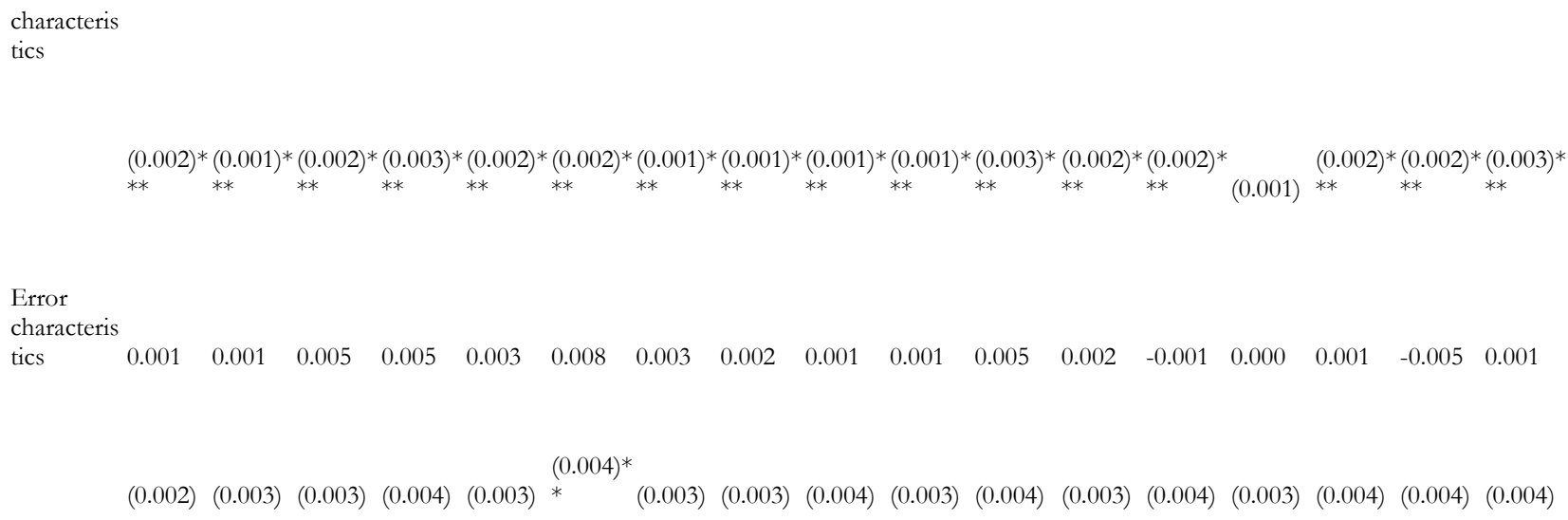


Error

characteris

$\begin{array}{lllllllllllllllllll}\text { tics } & 0.001 & 0.001 & -0.009 & -0.007 & -0.004 & -0.020 & -0.006 & -0.001 & 0.001 & 0.003 & -0.005 & 0.002 & -0.002 & 0.000 & -0.001 & 0.006 & 0.001\end{array}$

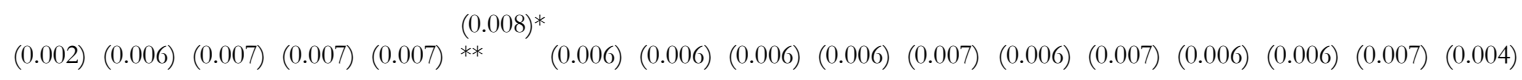

Wage

$\begin{array}{llllllllllllllllll}\text { structure } & 0.026 & 0.027 & 0.128 & 0.043 & 0.100 & -0.053 & 0.208 & 0.035 & -0.017 & 0.015 & 0.183 & 0.035 & -0.065 & -0.187 & -0.084 & -0.007 & 0.025\end{array}$

$(0.003) *(0.009) *(0.010) *(0.014) *(0.016) *(0.010) *(0.014) *(0.011) *$
$* *$
$* *$

Error wage

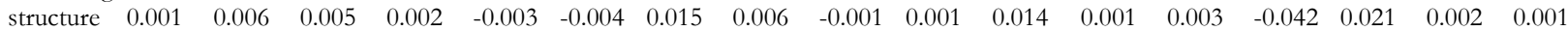

$(0.007)^{*}$

$\begin{array}{lllllllllllllll}(0.002) & (0.008) & (0.010) & (0.012) & (0.010) & (0.013) & (0.009) *(0.008) & (0.004) & (0.006) & (0.012) & (0.008) & (0.004) & * * & (0.011)^{*}(0.005) & (0.003)\end{array}$

Notes: Hourly wages are measured in euros considering regional purchasing power parities. The estimates corresponds to a specification of the wage equation that includes as control variables both individual characteristics (gender, age, education and nationality) and attributes of the job and the firm (tenure, type of contract, full- or part-time, supervisory tasks, occupation, sector, size, type of collective agreement, type of control, type of market, the proportion of females and immigrants in the firm, the proportion of workers with fixed-term contracts and with part-time in the firm, the proportion of workers working in unskilled and skilled occupations in the firm and the proportion of workers with primary and tertiary studies in the firm). ***, ** and $*$ indicate significance at the $1 \%, 5 \%$ and $10 \%$ levels, respectively.

TABLE A.6. Decomposition of raw inter-regional wage differences along the wage distribution in Spain. 2010. Fortin-Lemieux-Firpo methodology

$\begin{array}{cccccc}\text { Andalus } & \text { Balearic Canary Cantabr } & \text { C-La } & \text { C. y } & \text { Catalon Com.V Extrem } & \text { Galicia Madrid Murcia Navarra } \\ \text { ia Aasque } & \text { C. }\end{array}$

P 10

Overall

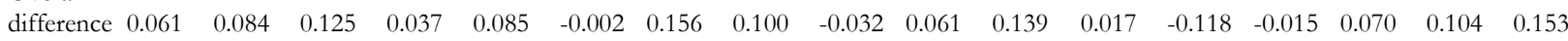

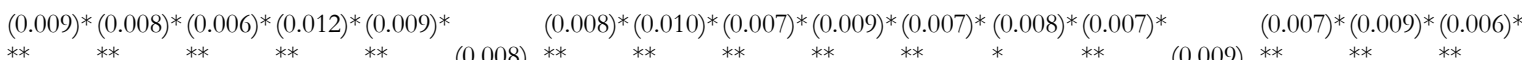

Compositi

on $\quad \begin{array}{llllllllllllllllll}0.004 & 0.006 & -0.002 & -0.027 & -0.021 & 0.019 & -0.003 & 0.005 & -0.007 & -0.000 & 0.004 & 0.006 & -0.004 & -0.010 & 0.023 & 0.045 & -0.008 & 0\end{array}$

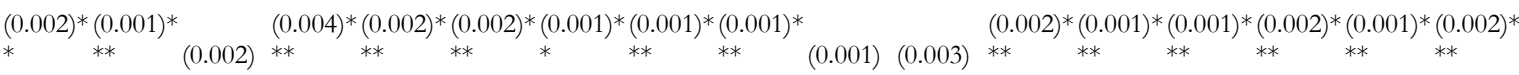

Individual

characteris

tics $\quad \begin{array}{lllllllllllllllll}0.001 & -0.001 & 0.003 & -0.008 & -0.003 & 0.001 & -0.002 & -0.000 & -0.002 & -0.000 & 0.002 & 0.000 & -0.000 & -0.003 & 0.003 & 0.007 & -0.002\end{array}$

(0.001) $(0.001)^{*}$

$(0.001) \quad(0.000)(0.001) *(0.001)(0.001)$

$(0.001)$

$(0.001) *(0.002) *(0.001) *(0.001) *(0.001) * \quad(0.000)^{*} \quad(0.001)^{*}(0.000)^{*}(0.001) *$

This article is protected by copyright. All rights reserved. 


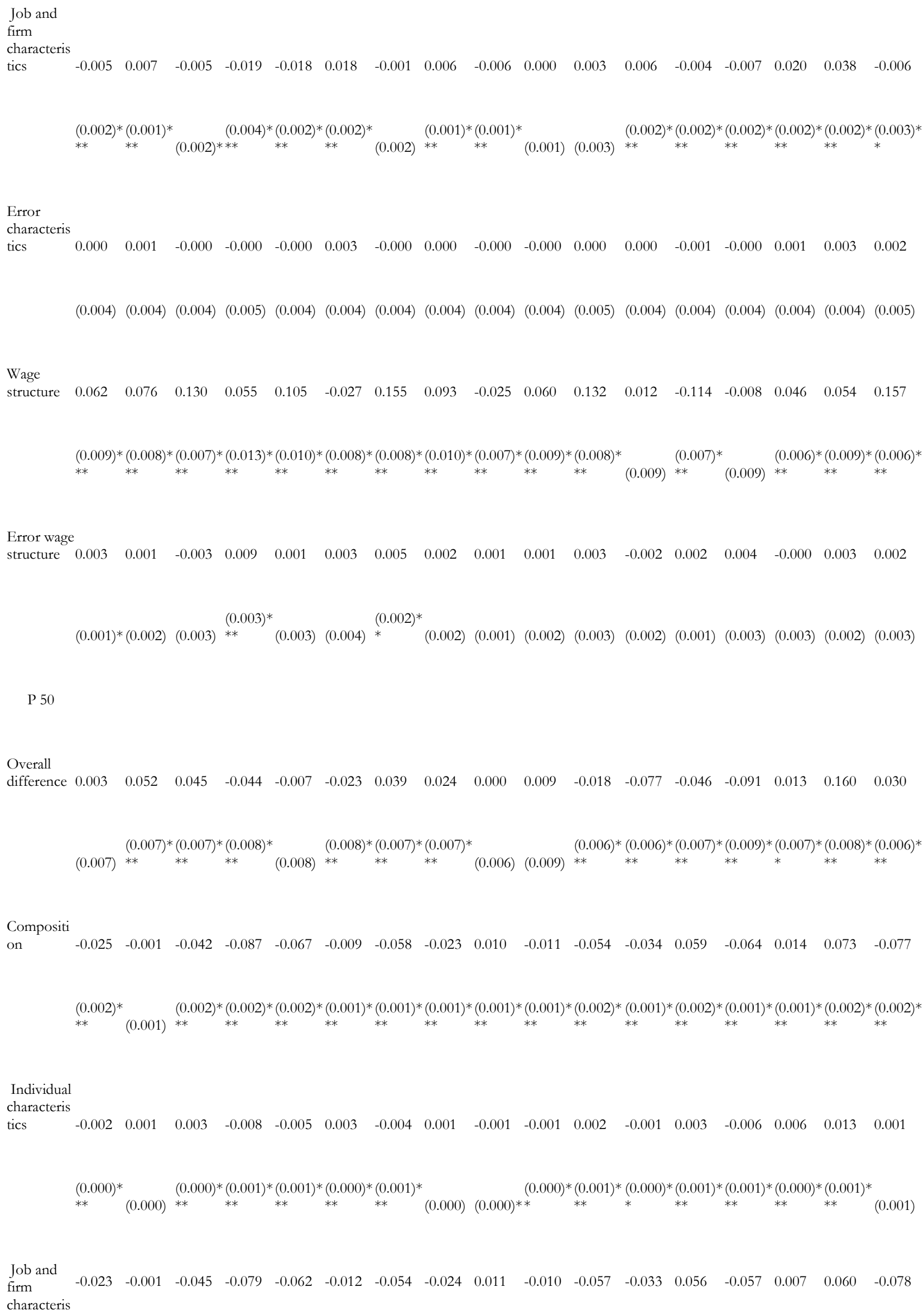


$(0.002) *$
$* *$

Error

characteris

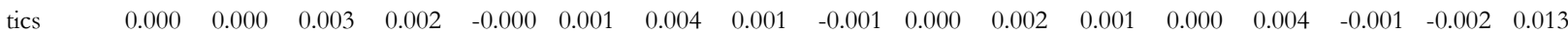

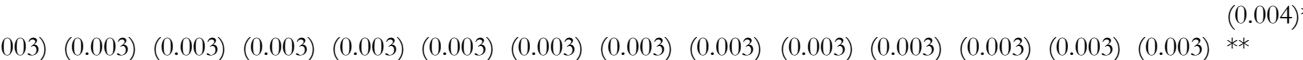

Wage

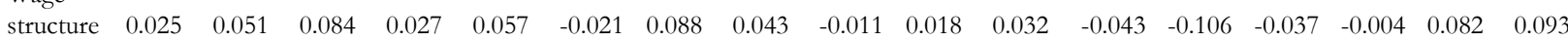

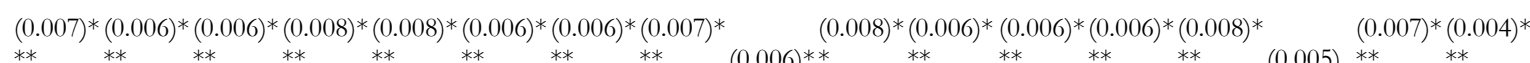

Error wage

$\begin{array}{llllllllllllllllll}\text { structure } & 0.003 & 0.001 & -0.001 & 0.014 & 0.004 & 0.005 & 0.005 & 0.004 & 0.001 & 0.002 & 0.003 & -0.001 & 0.001 & 0.006 & 0.004 & 0.006 & 0.002\end{array}$

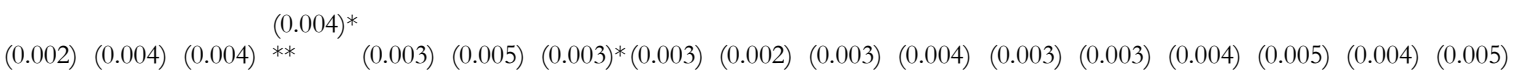

P 90

Overall

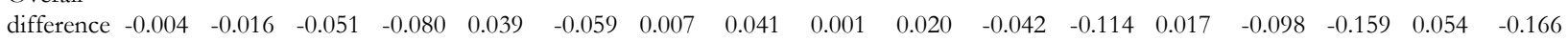

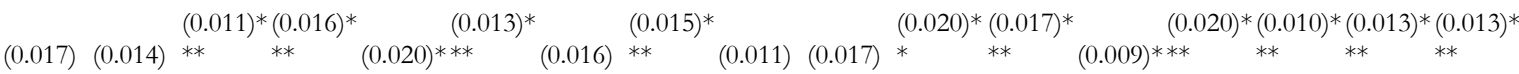

Compositi

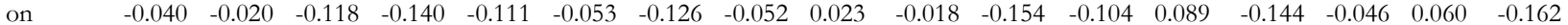

$(0.003) *(0.002) *(0.003) *(0.004) *(0.003) *(0.003) *(0.003) *(0.002) *(0.002) *(0.002) *(0.003) *(0.003) *(0.003) *(0.003) *(0.003) *(0.003) *(0.004) *$

** $* *$ ** ** ** ** ** ** ** ** ** ** ** ** ** ** **

Individual

characteris

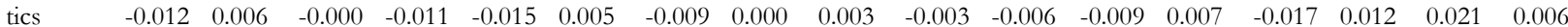

$(0.001) *(0.001) *$
$* *$

Job and

firm

characteris

$\begin{array}{lllllllllllllllllll}\text { tics } & -0.028 & -0.025 & -0.118 & -0.129 & -0.096 & -0.058 & -0.117 & -0.053 & 0.019 & -0.015 & -0.148 & -0.095 & 0.082 & -0.127 & -0.059 & 0.039 & -0.167\end{array}$

$(0.003) *(0.002) *(0.003) *(0.005) *(0.003) *(0.003) *(0.003) *(0.002) *(0.002) *(0.002) *(0.004) *(0.002) *(0.003) *(0.003) *(0.003) *(0.003) *(0.004) *$

This article is protected by copyright. All rights reserved. 


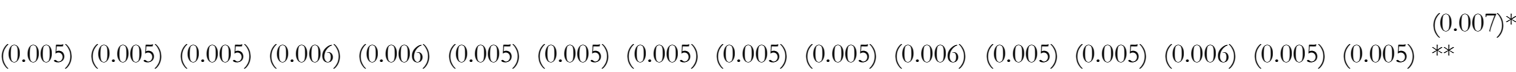

Wage

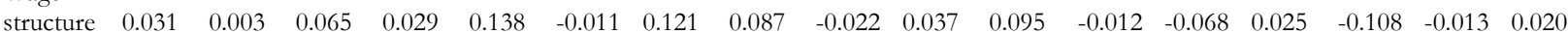

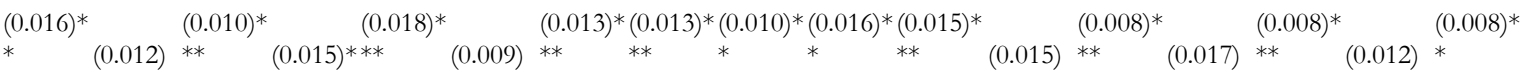

Error wage

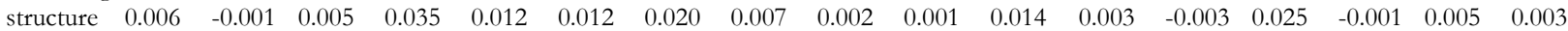

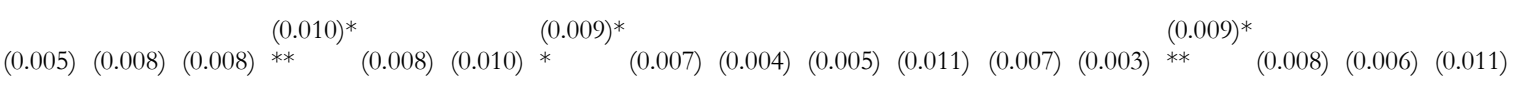

Notes: Hourly wages are measured in euros considering regional purchasing power parities. The estimates corresponds to a specification of the wage equation that includes as control variables both individual characteristics (gender, age, education and nationality) and attributes of the job and the firm (tenure, type of contract, full- or part-time, supervisory tasks, occupation, sector, size, type of collective agreement, type of control, type of market, the proportion of females and immigrants in the firm, the proportion of workers with fixed-term contracts and with part-time in the firm, the proportion of workers working in unskilled and skilled occupations in the firm and the proportion of workers with primary and tertiary studies in the firm). $* * *$, ** and $*$ indicate significance at the $1 \%, 5 \%$ and $10 \%$ levels, respectively.

TABLE A.7. Decomposition of raw inter-regional wage differences along the wage distribution in Spain. 2014. Fortin-Lemieux-Firpo methodology

$\begin{array}{ccccccc}\text { Andalus } & \text { Balearic Canary Cantabr } & \text { C-La } & \text { C. y } & \text { Catalon Com.V Extrem } & \text { Galicia Madrid Murcia Navarra Basque } & \text { Rioja } \\ \text { ia Aragon Asturias } & \text { Isl. Isl. ia } & \text { Man. León ia al. } & \text { iad. }\end{array}$

P 10

Overall

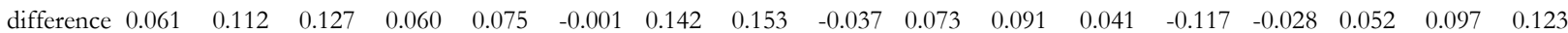

$(0.011) *(0.008) *(0.008) *(0.012) *(0.013) * \underset{(0.008)}{* *} \quad(0.009) *(0.009) *(0.008) *(0.011) *(0.009) *(0.009) *(0.007) *(0.010) *(0.008) *(0.012) *(0.007) *$

Compositi

on $\quad \begin{array}{llllllllllllllllll}0.016 & 0.010 & 0.008 & -0.022 & -0.032 & 0.006 & -0.015 & 0.005 & -0.003 & -0.009 & -0.030 & 0.003 & 0.006 & -0.013 & 0.032 & 0.051 & -0.005\end{array}$

$(0.001)^{*}(0.001) *(0.002) *(0.003) *(0.002) *(0.002)^{*}(0.002)^{*}(0.001)^{*}(0.001)^{*}(0.001)^{*}(0.003)^{*} \underset{* *}{* *}(0.002)^{* * *}(0.001)^{*}(0.001)^{*}(0.002)^{*}(0.002)^{*}(0.002)^{*}$

Individual

characteris

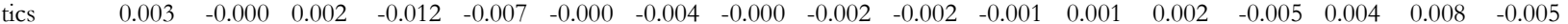

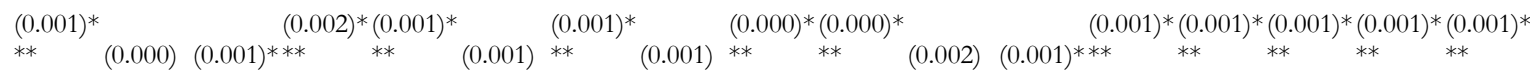




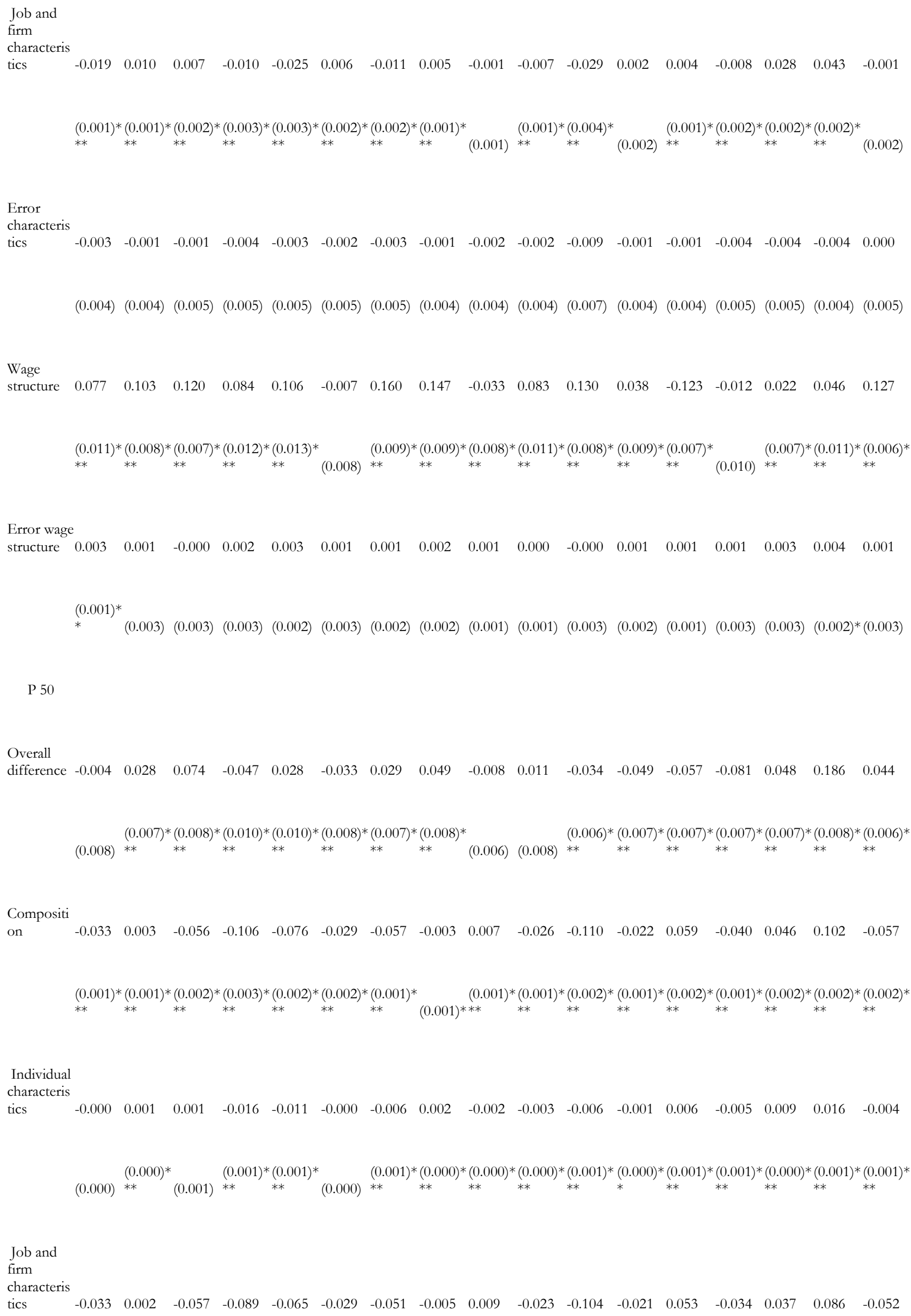




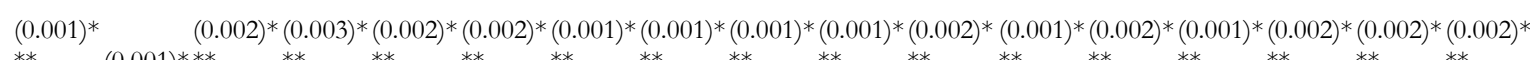

Error

\begin{tabular}{llllllllllllllllllll}
\multicolumn{2}{l}{$\begin{array}{l}\text { characteris } \\
\text { tics }\end{array}$} & 0.000 & 0.001 & 0.012 & 0.014 & 0.006 & 0.000 & 0.004 & 0.000 & 0.001 & -0.000 & 0.015 & 0.001 & -0.001 & 0.001 & -0.003 & -0.001 & 0.010
\end{tabular}

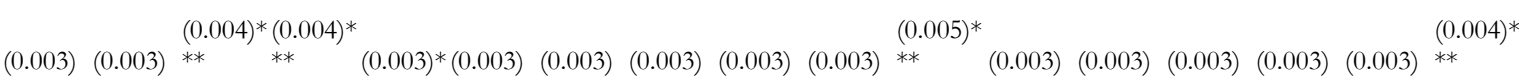

Wage

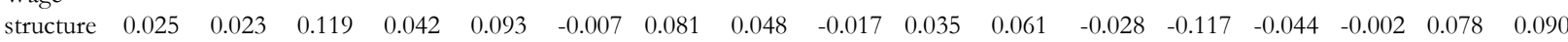

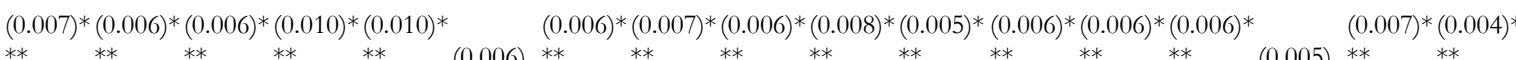

Error wage

$\begin{array}{lllllllllllllllllll}\text { structure } & 0.004 & 0.001 & -0.001 & 0.003 & 0.005 & 0.003 & 0.001 & 0.004 & 0.001 & 0.001 & -0.000 & -0.000 & 0.002 & 0.001 & 0.006 & 0.007 & 0.001\end{array}$

$(0.002) *(0.004)(0.003)(0.003)(0.003) *(0.005)(0.003)(0.003)(0.002)(0.002)(0.003)(0.003)(0.003)(0.004)(0.005) \quad(0.004) *(0.004)$

P 90

Overall

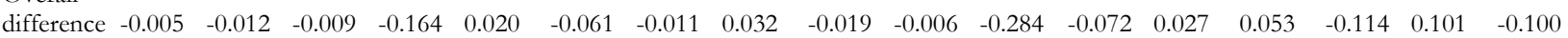

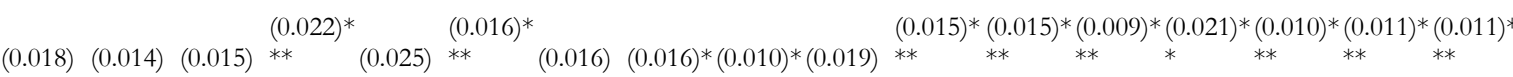

$\begin{aligned} & \text { Compositi } \\ & \text { on }\end{aligned}$
$\begin{array}{lllllllllllllllllll} & -0.053 & -0.013 & -0.139 & -0.235 & -0.139 & -0.074 & -0.122 & -0.023 & 0.006 & -0.036 & -0.201 & -0.065 & 0.076 & -0.065 & 0.009 & 0.091 & -0.108\end{array}$

$(0.002) *(0.002) *(0.003) *(0.005) *(0.003) *(0.003) *(0.003) *(0.002) *(0.002) *(0.002) *(0.004) *(0.002) *(0.003) *(0.003) *(0.003) *(0.003) *(0.004) *$

Individual

characteris

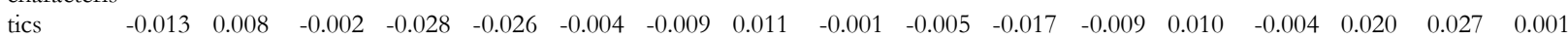

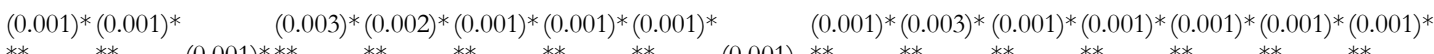

** $\quad * * \quad(0.001)^{* * *} \quad * * \quad * * \quad * * \quad * * \quad(0.001) * * \quad * * \quad * * \quad * * \quad * * \quad * * \quad * * \quad(0.002)$

Job and

firm

characteris

tics $\quad \begin{array}{rllllllllllllllll}-0.041 & -0.021 & -0.137 & -0.207 & -0.113 & -0.070 & -0.113 & -0.034 & 0.007 & -0.031 & -0.184 & -0.055 & 0.067 & -0.061 & -0.011 & 0.064 & -0.109\end{array}$

$(0.002) *(0.002) *(0.004) *(0.006) *(0.003) *(0.003) *(0.003) *(0.002) *(0.002) *(0.002) *(0.005) *(0.002) *(0.003) *(0.003) *(0.003) *(0.003) *(0.004) *$

$\begin{array}{llllllllllllllllll}\text { Error } & 0.003 & 0.002 & -0.020 & -0.015 & -0.006 & 0.001 & -0.009 & 0.002 & 0.000 & 0.002 & -0.058 & 0.005 & 0.002 & 0.004 & -0.000 & 0.005 & -0.031\end{array}$

This article is protected by copyright. All rights reserved. 


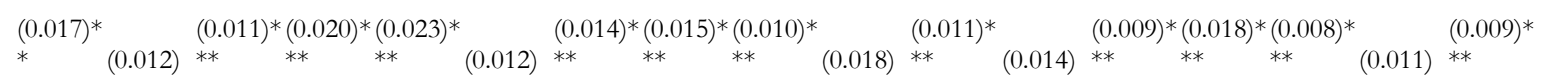

Error wage

$\begin{array}{llllllllllllllllll}\text { structure } & 0.006 & 0.001 & -0.001 & 0.005 & 0.009 & 0.009 & 0.004 & 0.008 & 0.002 & 0.002 & 0.004 & -0.000 & -0.000 & 0.004 & 0.007 & 0.001 & -0.000\end{array}$

Notes: Hourly wages are measured in euros considering regional purchasing power parities. The estimates corresponds to a specification of the wage equation that includes as control variables both individual characteristics (gender, age, education and nationality) and attributes of the job and the firm (tenure, type of contract, full- or part-time, supervisory tasks, occupation, sector, size, type of collective agreement, type of control, type of market, the proportion of females and immigrants in the firm, the proportion of workers with fixed-term contracts and with part-time in the firm, the proportion of workers working in unskilled and skilled occupations in the firm and the proportion of workers with primary and tertiary studies in the firm). ${ }^{* * *}$, ** and * indicate significance at the $1 \%, 5 \%$ and $10 \%$ levels, respectively.

i Other studies that also apply this methodology are López-Bazo and Motellón (2012) for Spain and Kluge and Weber (2018) for Germany.

ii Moreover, there could be some controversy as regards this point, given that some authors argue that there might be some problems in the identification of worker fixed-effects when estimating spatial wage differentials and that, as a result, the use of observable characteristics of workers related to human capital and socio-economic characteristics is preferable (Groot et al., 2014).

iii Accordingly, we follow Oaxaca and Ramson (1994) and Neumark's (1988) recommendation to use as the reference wage that which corresponds to the pool of individuals of both groups. Moreover, a dummy variable relating to the group belonging to each observation is included in the estimation, given that failure to include this variable could lead to bias in the breakdown, such as overvaluation of the characteristics component and the corresponding underestimation of the returns component caused by the omission of specific intercepts for each group (Elder, Goddeeris and Harris, 2010).

iv Following Barsky et al. (2002), who suggest that these non-linearities could exist even in the case of the estimation of wage equations via ordinary least squares, the Di Nardo et al. (1996) reweighting procedure has also been applied in the empirical analysis for the decomposition of average wages with the standard Oaxaca-Blinder decomposition. 
v In estimating the probit the same covariates than in equation (1) have been employed.

vi To test for the statistical significance of the different elements of both the composition and wage structure effects, standard errors have been estimated by bootstrapping considering 100 replications.

vii Given that in our analysis the region of reference of each individual corresponds to the region where the workplace where he/she works is located, it might not match in some cases with the region of residence. Yet, it must be noted that the incidence of commuting between adjacent regions (NUTS 2 units) is very low in the case of Spain, given that it affects only to $2.7 \%$ of male employees and $1.6 \%$ of female employees, being among the lowest of the whole European Union (Eurostat, 2016).

viii This early estimation of regional purchasing power parities conducted in 1989 for Spain is based on the Encuesta de Precios Regionales (Regional Price Survey) and it has been used in previous analyses on inter-regional wage differentials in Spain (Simón et al., 2006; Motellón et al., 2011). Yet, it presents relevant shortcomings, given that the prices of each region were originally approximated from those of the capital city (more details can be found in Lorente, 1992).

ix Specific analyses on the influence of these factors on wages in Spain can be found in Simón et al. (2008), Simón, Sanromá and Ramos, (2017) and Simón (2010, 2012).

x According to additional robustness checks carried out, the use of regional purchasing does not seem to imply substantial changes in the results of the decomposition of regional average wage differences. Accordingly, it does not affect neither the pure composition effect (including its size and the relative contribution of different subgroups of covariates) nor the two error terms. The only significant modification induced by regional power parities occur in the wage structure components, whose changes seem to be completely due to this element. This evidence is available on request to authors.

This article is protected by copyright. All rights reserved. 